\title{
The Paganini Variations: A Study of Selected Works by Liszt, Brahms, Rachmaninoff, Lutoslawski, and Muczynski
}

Youna Choi

Follow this and additional works at: https://researchrepository.wvu.edu/etd

\section{Recommended Citation}

Choi, Youna, "The Paganini Variations: A Study of Selected Works by Liszt, Brahms, Rachmaninoff, Lutoslawski, and Muczynski" (2017). Graduate Theses, Dissertations, and Problem Reports. 5361.

https://researchrepository.wvu.edu/etd/5361

This Dissertation is protected by copyright and/or related rights. It has been brought to you by the The Research Repository @ WVU with permission from the rights-holder(s). You are free to use this Dissertation in any way that is permitted by the copyright and related rights legislation that applies to your use. For other uses you must obtain permission from the rights-holder(s) directly, unless additional rights are indicated by a Creative Commons license in the record and/ or on the work itself. This Dissertation has been accepted for inclusion in WVU Graduate Theses, Dissertations, and Problem Reports collection by an authorized administrator of The Research Repository @ WVU.

For more information, please contact researchrepository@mail.wvu.edu. 


\title{
The Paganini Variations: A Study of Selected Works by \\ Liszt, Brahms, Rachmaninoff, Lutoslawski, and Muczynski
}

\author{
Youna Choi \\ A Doctoral Research Project submitted to the \\ College of Creative Arts \\ at \\ West Virginia University \\ in partial fulfilled of the requirements for the degree of \\ Doctor of Musical Arts \\ in \\ Piano Performance
}

\author{
James Miltenberger, D.M.A., Chair and Research Advisor \\ Peter Amstutz, D.M.A. \\ William Haller, D.M.A. \\ Andrea Houde, G.P.D, M.M \\ Joy Saab, Ed.D. \\ School of Music \\ Morgantown, West Virginia \\ 2017
}

Keywords: Paganini variations, Liszt Paganini, Brahms Paganini, Rachmaninoff Paganini, Lutosławski Paganini, Muczynski Paganini, Performance guide

(C) 2017 Youna Choi 


\section{ABSTRACT \\ The Paganini Variations: A Study of Selected Works by Liszt, Brahms, Rachmaninoff, Lutosławski, and Muczynski \\ Youna Choi}

Caprice in A minor, Op. 1, No. 24 for solo violin by Niccolò Paganini has been a great inspiration for many composers. This study investigates five compositions that are based on the Paganini theme: Liszt, Brahms, Rachmaninoff, Lutosławski, and Muczynski. Although these five composers utilized the same melodic material as their compositional source, their works are stylistically much different, from a typical nineteenth century idiom used by Liszt to the jazzinspired harmony used by Muczynski.

Each chapter includes a general background and analytical aspects of the individual work, and is followed by performance guidelines. The performance guidelines not only deal with technical problems such as fingering, phrasing, hand distribution, but also provide stylistic suggestions when needed. 
TABLE OF CONTENTS

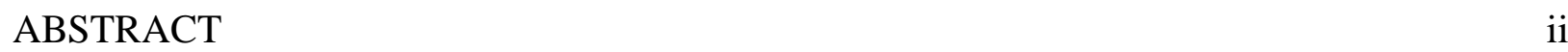

CHAPTER ONE: INTRODUCTION AND BACKGROUND

1. Scope and Purpose of the Study 1

2. Review of Related Literature 2

3. Caprice in A minor, Op. 1, No. 24 (1802-17) for Solo Violin by Niccolo Paganini 7

CHAPTER TWO: GRANDES ETUDES DE PAGANINI, S. 141 (1851) BY FRANZ LISZT

1. Background 9

2. General Analysis and Comparison 11

2.1. $\quad$ Formal Structure

2.2. $\quad$ Texture

2.3. Harmony

2.4. $\quad$ Comparison with Paganini’s Original Caprice

3. Pedagogical Suggestions 14

3.1. Level of difficulty

3.2. Performance and Pedagogical Guidelines

CHAPTER THREE: VARIATIONS ON A THEME BY PAGANINI, OP. 35 (1862-63) BY JOHANNES BRAHMS

1. Background 22

2. General Analysis $\quad 24$

2.1. Key, Structural and Stylistic Designs

2.2. Meter, Rhythm, and Tempo Relationship

2.3. Texture

3. Pedagogical Suggestions 27

3.1. Level of Difficulty 
3.2. Performance Option

3.3. Performance and Pedagogical Guidelines

CHAPTER FOUR: RHAPSODY ON A THEME BY PAGANINI, OP. 43 (1934) BY SERGEI RACHMANINOFF

1. Background 34

2. General Analysis 35

2.1. Structural and Stylistic Designs

2.2. Harmonic Idioms and Tonality

2.3. Theme and Other Melodic Figures

$\begin{array}{ll}3 . & \text { Pedagogical Suggestions }\end{array}$

3.1. Level of Difficulty

3.2. Performance Options and Pedagogical Guidelines

CHAPTER FIVE: VARIATIONS ON A THEME BY PAGANINI FOR TWO PIANOS (1940-41), FOR PIANO AND ORCHESTRA (1978) BY WITOLD LUTOSŁAWSKI

1. Background 48

2. General Analysis $\quad 50$

2.1. Structure

2.2. Harmony and Tonality

2.3. Rhythm, Tempo, and Dynamics

3. Pedagogical Suggestions 55

3.1. Level of Difficulty

3.2. Performance and Pedagogical Guidelines

CHAPTER SIX: DESPERATE MEASURES FOR PIANO, OP. 48 (1994) BY ROBERT MUCZYNSKI

$\begin{array}{lll}\text { 1. } & \text { Background } & 60\end{array}$

2. General Analysis 62

2.1. Theme 
2.2. Structure

2.3. Harmony

2.4. Meter and Rhythm

3. Pedagogical Suggestions

3.1. Level of Difficulty

3.2. Performance and Pedagogical Guidelines

CHAPTER SEVEN: SUMMARY AND CONCLUSION

APPENDIX 


\section{CHAPTER ONE: INTRODUCTION AND BACKGROUND}

\section{SCOPE AND PURPOSE OF THE STUDY}

Caprice in A minor, Op. 1, No. 24 for solo violin by Niccolò Paganini has long been popular among many composers from the nineteenth century to the present day. The powerful and exciting theme of the composition gave inspiration to various composers such as Johannes Brahms, Franz Liszt, Sergei Rachmaninoff, Witold Lutoslawski, Robert Muczynski, and many others. Although there are numerous composers who borrowed the Paganini tune for their own sets of variations (see Appendix), this paper focuses on five major compositions that are fairly significant in piano literature:

- Liszt: Grandes Etudes de Paganini, S. 141 (1851)- revised version of Études d'exécution transcendante d'après Paganini, S.140 (1838)

- Brahms: Variations on a Theme by Paganini, Op. 35 (1862-63)

- Rachmaninoff: Rhapsody on a Theme by Paganini, Op. 43 (1934)

- Lutosłaski: Variations on a Theme by Paganini for two pianos (1940-41), and for piano and orchestra (1978)

- Mucyznski: Desperate Measures (Paganini Variations) Op. 48 (1994)

The purpose of this study is to analyze and compare these five compositions and to provide appropriate performance and teaching guidelines. Much of the existing research deals with formal and analytical aspects of these works or briefly mentions pedagogical concerns of a particular composition. In this study, the analysis and comparison will proceed by looking at basic musical principles, such as melodic contour, rhythm, and formal structure, as well as harmonic idiom and variation procedure. In addition to the analysis and comparison, this paper will also explore pedagogical guidelines for each composition, which will hopefully be a helpful resource both for performers and teachers. The level of difficulty and challenges of each 
composition will be addressed, and applied exercises and practical performance practice will be discussed. Therefore, this study will provide not only the understanding of formal analysis of the pieces, but also practical guidelines for how to perform the works effectively.

\section{REVIEW OF RELATED LITERATURE}

There are some helpful dissertations that talk about the selected composition(s). However, none of the research deals with both analyses and performance practices of the five selected pieces. The sources reviewed in this study mainly include books and dissertations.

Steward Gordon's book A History of Keyboard Literature: Music for the Piano and its Forerunners provides a concise biography of composers and general information about the variations by Liszt and Brahms.

The following sources mention the comparison of some of the selected works:

Wenli Zhou wrote, “Piano Variations by Liszt, Lutosławski, Brahms, and Rachmaninoff on a Theme by Paganini,” in 2012 as her DMA dissertation. It is divided into seven chapters: an introduction, in-depth analyses of the variations by each composer, and a conclusion. Before talking about the variations by the four composers above, Zhou begins with the analysis of Niccolo Paganini’s original twenty-fourth caprice for violin. Zhou mainly focuses on the analytical aspect of these five compositions by considering musical elements such as form, harmony, rhythm, texture, key, etc.

“The Influence of the Theme and Variation of Paganini’s 'Caprice No. 24’ from ‘Twenty-four Caprices for Solo Violin’ on Two Major Piano Solo Works: Liszt 'Grandes etudes 
de Paganini No. 6 in A minor, S. 140’ and Muczynski 'Desperate Measures (Paganini Variations) for piano, Op. 48’”, DMA diss., by Szu-Ting Chou, focuses specifically on the melodic contour, rhythm, and structure between the sets in order to compare and contrast each composer's manipulation of Paganini’s original theme.

Benita Wan-Kuen Tse also contributed researching the influence of Paganini’s Caprice No. 24. Her DMA thesis, "Piano Variations Inspired by Paganini’s Twenty-Fourth Caprice from Op. 1” begins with an introductory chapter that includes a brief discussion of the origin of the variation form and musical aesthetics of the nineteenth century, followed by a chapter on the historical background of Paganini's twenty-fourth caprice and its influence on other composers. The author selects Liszt's Grandes etudes de Paganini No. 6; Busoni's Paganini-Liszt Thema Mit Variationen, Etuden No. 6: "Eine Transkription-Studie von Ferruccio Busoni"; Brahms's Variations on a Theme by Paganini, Op. 35; Lutosławski's Wariacje Na Temat Paganiniego; and Rachmaninoff's Rhapsody on a Theme by Paganini, Op. 43 as examples, and provides a careful examination of each composer's individual style of writing and their different approaches to transcription techniques. Each of the five piano works is analyzed in terms of historical background, pianistic devices, and variation and transcription techniques.

Another interesting source of material can be found in a Ph. D dissertation by Gillian Robertson, "Variations on a Theme by Paganini: Narrative Archetypes in Nineteenth-andTwentieth-Century Theme-and-Variation Sets.” This dissertation explores the applicability of musical narrative models to the genre of theme and variations by focusing on large-scale structural transformations in theme-and-variation sets of the nineteenth and twentieth centuries. Robertson mentions the first book of Brahms’ Variations on a Theme by Paganini, Op.35 and 
Rachmaninoff's Rhapsody on a Theme of Paganini, Op.43, and provides detailed analyses of these two compositions.

While these sources mention comparisons between two or more selected pieces, the following dissertations explore analytic and/or pedagogical aspects of a specific composition:

In his dissertation, "A Study Guide to Franz Liszt's "Grandes Etudes de Paganini" S.141”, Javier Clavere basically provides two main ideas: analytical viewpoint with a brief background of the composition, and practice suggestions for Liszt's Paganini Etudes. Clavere elaborates the study guide by explaining elements of technical problems, hand subdivision, and parsing of the score for memorization. The dissertation also examines the physical-technical aspects of practicing etudes, specifically, helpful exercises and the finger regimen needed for physical preparation of these etudes for performance.

Ian Henry Altman wrote his DMA dissertation on Liszt’s Paganini Etudes in 1984 under the title of "Liszt’s Grand Etudes after Paganini: A Historical and Analytical Study.” Altman provides detailed analysis of all six pieces in Chapters II and III, and also includes a discussion on performance practice and mentions the Busoni Edition.

In 1999, Younshin Kim published her DMA dissertation “An Analytical Study of Liszt’s Grandes Etudes de Paganini, Nos. 3 and 6.” In this paper, Kim only mentions No. 3 “La Campanella" and No. 6. The dissertation explores the process of Liszt's stylistic development through examination of these two selected pieces. Kim compares them with Paganini’s original violin caprices, Liszt’s Grande Fantasie de bravoure sur la clochette, S. 420 (1832-34), Études d'exécution transcendante d'après Paganini, S. 140 (first version composed in 1838), and Grandes Etudes de Paganini, S. 141 (second version revised in 1851). This source does not 
provide performance practices but includes analysis and makes interesting comparisons between different versions so that it helps for readers to grasp the stylistic development that Liszt chose.

“Variation Procedure in Rachmaninoff's Piano Works” by Chien Chou provides excellent information on the general characteristic of Rachmaninoff's variation procedures before turning to in-depth study of Rhapsody on a Theme by Paganini, Op. 43. Chou analyzes the work in three sections and raises a few debatable questions, such as the stop/start dilemma in variation form, and the use of "Rhapsody" in the title instead of "Variations".

Jay Alan Hershberger wrote his DMA dissertation on Rachmaninoff's four Piano Concertos and Rhapsody on a Theme by Paganini. Hershberger provides general background information for each work and analyzes them by considering musical architecture, phrasing, voicing, articulation, the "technical sweep," dynamics, etc. With these elements being considered analytically, this source indirectly gives readers a sense of performance-practice consideration.

A helpful resource for a performance guide on Rachmaninoff's Rhapsody is provided by Cha-Hui Ko in her DMA dissertation, "Solutions to Technical Difficulties in the Rhapsody on a Theme by Paganini, Opus 43 of Rachmaninoff.” Ko includes biographical information on the composer and his life as composer and pianist, as well as stylistic characteristics of his piano music in Chapter Two. Chapter Three exclusively deals with appropriate solutions to technical difficulties and performance guides for the introduction, each of the twenty-four variations, and the coda. 
Ying Zhang wrote her DMA dissertation, “A Stylistic, Contextual, and Musical Analysis of Rachmaninoff's Rhapsody on a Theme of Paganini, Op. 43” in 2008. This document explores the use of the theme from Paganini's twenty-fourth caprice and the Dies Irae in Rachmaninoff's Rhapsody. The two themes are studied from a historical and musical perspective, and their contribution to the work’s dramatic and musical development is analyzed. Chapter Five has an extensive musical discussion of each of the twenty-four variations, where phrase structure, thematic relations, harmonic and melodic shapes, rhythmic patterns, dramatic implications, and performance challenges are discussed.

Another interesting document on Rachmaninoff's Rhapsody was written by Heejung Kang, “Rachmaninoff's Rhapsody on a Theme by Paganini, Op. 43: Analysis and Discourse.” The entire thesis focuses on this particular composition and provides in-depth information about the piece including historical background, detailed analysis, discussion on Dies Irae, philosophical interpretation, and performance practice and interpretation.

Lutoslawski’s Variations on a Theme by Paganini is another significant work for piano and orchestra or for two pianos in addition to Rachmaninoff's Rhapsody. Ling Chao Chen’s dissertation, “An Analysis of Witold Lutoslawski’s Variations on a Theme by Paganini for Two Pianos and an Original Composition Concerto for Two Pianos and Orchestra," explores a detailed analysis preceded by a concise history of Lutoslawski’s life. The analysis focuses on harmony, dynamics, counterpoint, rhythm, form and general texture of the work. The dissertation is divided into two parts: the first part is on the variation and the second part is on the concerto. 
Kimono Monique Bernier wrote, “Desperate measures: Two 20th Century Treatments of the Paganini Theme” in 2000 as her DMA dissertation. This document investigates the significance of the Paganini theme and variation sets composed by two living composers, Neils Viggo Bentzon and Robert Muczynski. Bernier discusses the two composers’ contrasting treatments of the theme as she demonstrates by analyzing melody, texture, rhythm, register, and structure/form. It includes a detailed analysis yet does not provide any pedagogical suggestions.

“An Analytical Study of the Variations on the Theme of Paganini’s Twenty-fourth Caprice, Op. 1 by Busoni, Friedman, and Muczynski” by Kwang Sun Ahn provides an analysis along with general information about the composer and their compositional styles.

While there have been many studies that discuss several piano works that are based on the Paganini theme and provide interesting aspects in analytical and sometimes in pedagogical point of view, surprisingly none of them compare all five compositions that are going to be explored in this paper. The five selected compositions are written by major composers in piano literature; they are very well-known and are considered as staple pieces in recital and concert repertoires. Hopefully, many teachers and pianists can benefit from this information on formal structure with teaching guidelines for each of these five popular works for performance preparation.

\section{CAPRICE IN A MINOR, OP. 1, NO. 24 BY NICCOLO PAGANINI}

The Twenty-four Caprices for solo violin were written between 1802 and 1817. Paganini wrote these caprices in groups. The first and second sets each contain six caprices, and twelve caprices are in the last set. These were written in the style of etude, with each exploring different skills such as double-stopped trills and extremely fast shift of positions or strings. 
The twenty-fourth caprice is the most well-known one. It is in A minor, and written in a form of theme and variations (a theme and eleven variations, and a finale). While leaving the harmonic structure established in the theme fairly simple, each of the eleven variations explores a new technique of either the right or left hand, and Paganini's own virtuosity is evident in the level of difficulty maintained throughout the work. ${ }^{1}$

\section{Theme}

The theme is 16 measures long, in binary form. The first four measures (A section) are repeated, followed by another eight measures (B section). The B section progresses through the circle of fifths at first. All eleven variations exactly follow this form except for the last variation (Variation 11). Paganini alters the final cadence of this variation leaving one measure short, and this variation is connected to the finale.

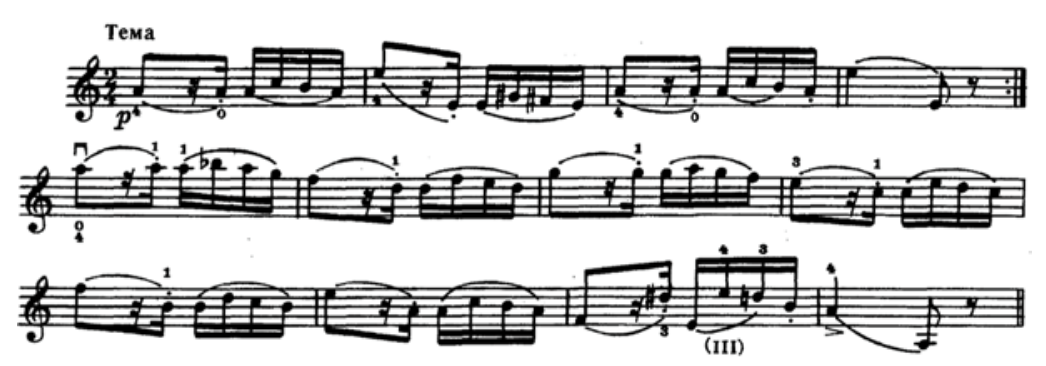

\footnotetext{
${ }^{1}$ Wenli Zhou, "Piano Variations by Liszt, Lutosławski, Brahms, Rachmaninoff on a Theme by Paganini” (D.M.A. diss., Rice University, 2012), 9.
} 


\section{CHAPTER TWO: \\ GRANDES ETUDES DE PAGANINI, S. 141 (REVISED 1851), NO. 6 \\ BY FRANZ LISZT}

\section{BACKGROUND}

The Grandes Etudes de Paganini, S. 141 is the revised version of the Études d'exécution transcendante d'après Paganini, S.140, which was published at the end of 1840. Both versions were dedicated to Clara Schumann. The Grandes Etudes de Paganini is a set of six etudes that are all based on the violin compositions of Niccolò Paganini. The sixth etude is after the twentyfourth caprice of Paganini. This chapter will mention only the sixth etude.

Franz Liszt (1811-1886) first heard Paganini in April 1831, and was tremendously impressed by his playing and his ability to use a technique of legendary transcendence for utterly musical purposes. Liszt immediately proclaimed his intention of achieving upon the piano an equivalent new technical mastery in order to unleash musical thoughts which had remained inexpressible before. $^{2}$

According to Ben Arnold in his book, The Liszt Companion, Liszt followed the same structure and melodic materials as Paganini’s A minor caprice, adopting for the keyboard the material Paganini wrote so idiomatically for the violin. The two versions of this etude have significant changes in almost every variation; even the theme itself is simplified in the revised version, with single notes replacing the octaves. Liszt simplifies some of the incredibly difficult passages of the first versions, namely the nearly unplayable parallel tenths in the alternate passage in Variation 6 (Figure 2.1), the treacherous rolled chords in Variation 8 (Figure 2.2), and

\footnotetext{
${ }^{2}$ Leslie Howard, Liner Notes, The Complete Music for Solo Piano, Vol. 48: Liszt- The Complete Paganini Études, Leslie Howard (piano), Hyperion CDA 67193, 1998, CD.
} 
some intricate leaps in the last variation. He completely rewrites Variation 2, omitting the countermelody begun in the fifth measure of the original version and removes the four-againstthree rhythmic pattern of the first version in the fourth variation. The final version, nevertheless, retains much of the original virtuosity and includes brilliant writing for the piano with examples of extended trills, alternating chords, open octaves, parallel thirds, and four-octave arpeggios. ${ }^{3}$
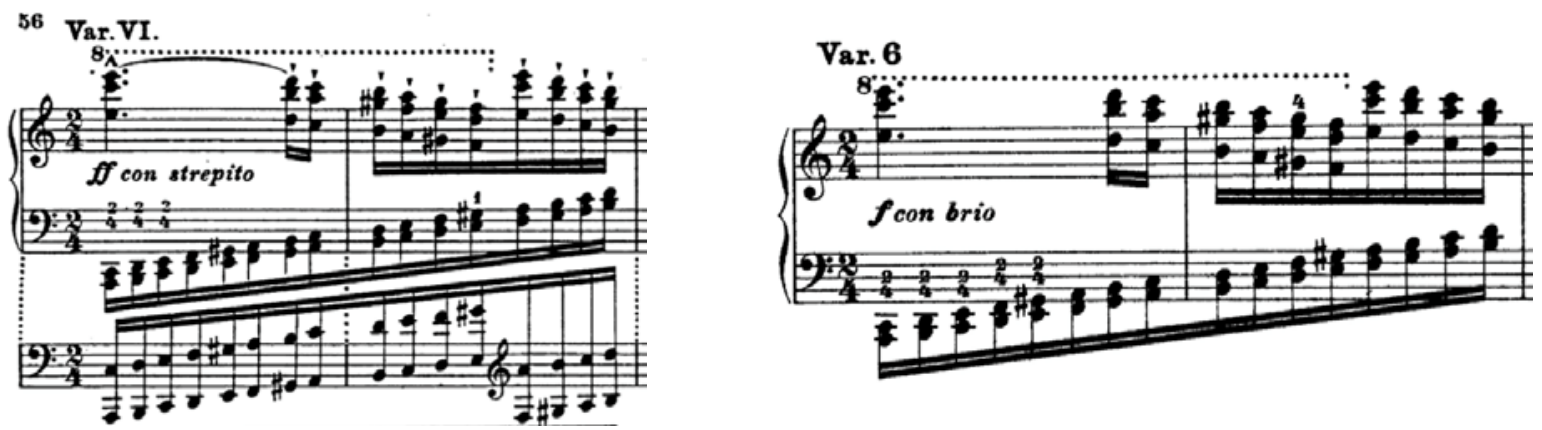

[Figure 2.1] Variation 6 of the first version and the second version
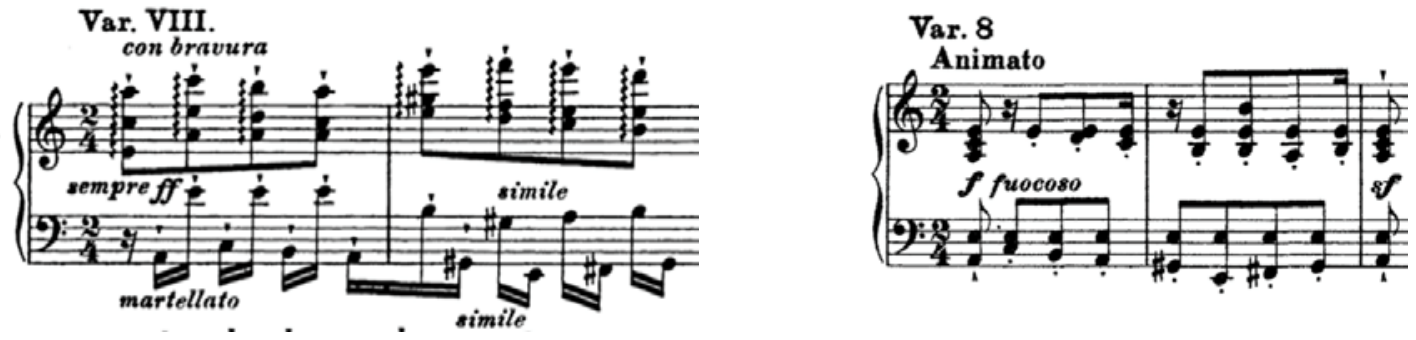

[Figure 2.2] Variation 8 of S. 140 and S. 141

Between the two versions, the revised version is played more frequently. The earlier version is treacherously difficult technique-wise with wide skips and stretches which Liszt took away and replaced with simpler figures for the later version.

\footnotetext{
${ }^{3}$ Ben Arnold, The Liszt Companion (Westport, CT: Greenwood Press, 2002), 103.
} 


\section{GENERAL ANALYSIS AND COMPARISON}

A comparison of Liszt's sixth etude with Paganini's twenty-fourth caprice reveals it is almost identical, as if Liszt transcribed the violin writing to the piano version with pianistic challenges - clarity, octaves, trills, arpeggios, leaps, alternating hands, and etc. The thematic, harmonic, melodic, and formal structures are the same as the violin caprice. Therefore, among the selected five compositions, Liszt's set remains the most true to the original caprice of Paganini.

\subsection{Formal Structure}

The formal layout of Paganini’s caprice is a twelve-measure-long theme followed by eleven variations. Liszt follows the same structure as the caprice with the exception of Variation 11 which leads to the coda. In general, the formal structure as well as the harmonic structure is straightforward. Liszt only made minor changes: Cadential extension in Variation 2 and the coda. Liszt's Etude is longer in length than the caprice. He added repeats in many places. For example, Variations 2, 3, 5, 8, 10 and 11 have repeats of the A section. Variation 2 has repeats of both A and B sections.

\section{$\underline{2.2 \text { Texture }}$}

As Liszt adds extra melodies and harmonies to the original material, these new additions create a new textural layer. One of the obvious examples is the seventh variation. Liszt follows Paganini's original melody but doubles it two octaves below in the left hand. Each line of the two-voiced texture is set to imitate orchestral instruments. In the first edition, Liszt marked quasi flauto for the top voices and quasi Fagatto for the lower voices. ${ }^{4}$

\footnotetext{
${ }^{4}$ Zhou, 26.
} 
The tenth variation also shows multi layers of sound with a long textural trill. For the caprice, this variation is probably one of the least challenging variations. Yet, Liszt's piano version requires pianists to have independence of fingers in order to control different voices simultaneously. ${ }^{5}$

\section{$\underline{2.3 \text { Harmony }}$}

Liszt made various harmonic changes in multiple ways. Paganini generally replaced the implied Italian sixth chord in the cadence of the theme with the diminished ii chord in most of his variations. Liszt replaced the Italian sixth chord with the French sixth chord. In the eighth variation, Liszt uses a viiº/V instead of Paganini’s Italian sixth chord.

\subsection{Comparison with Paganini’s Caprice}

The following analysis is based on the second version (S. 141), and compared with Paganini’s violin caprice.

Among the five compositions mentioned in this paper, Liszt is the only one who treats the theme more aggressively. The chords on the downbeat that Liszt used are relatively thicker than the other four compositions (figure 2.3). Although Liszt made major revisions for the second version, he preserved these big rolled chords from the first version.

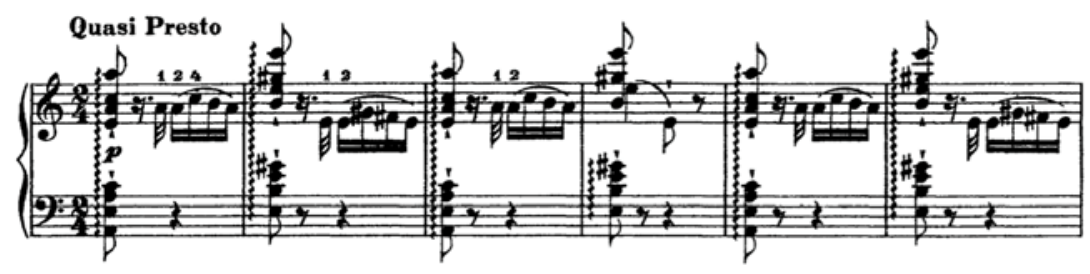

[Figure 2.3] Theme

\footnotetext{
${ }^{5}$ Zhou, 29.
} 
- Variation 1: Liszt used Paganini’s original material in the right hand, but added extra chords. Also, the theme appears in the left hand.

- Variation 2: This variation showcases a hand distribution. At the repeat of the B section, the melody is in the left hand and supporting chords are in the right hand. The melody starts two octaves lower than Paganini's caprice, then moves up. The closing cadence is extended with a brief codetta after the fermata.

- Variation 3: The melody from the caprice is embedded in the bass as foundation while the theme bounces in the top voice.

- Variation 4: Liszt changes the chromatic melodic figure to octaves, which displays pianistic challenge. Executing these descending octaves is especially challenging when it needs to be legato. While the chromatic melody glides on top, the simplified version of the theme bounces in the left hand.

- Variation 5: This variation displays the acrobatic skill of a performer. The interval between each downbeat and the following chord is more than two octaves apart. Liszt made an adjustment to the last eighth note in each measure. The eighth notes now become triplets.

- Variation 6: The descending melody is in the right hand with added octaves while a series of thirds in the left hand moves in a contrary motion. These thirds become octaves in a repeat of the A section. In the B section, the thirds and octaves change consecutively. Paganini's caprice has a series of parallel tenths in the B section. Liszt, however, limits the maximum interval to octaves.

- Variation 7: An extra chord is added between the quarter note and the triplet, which also suggests acrobatic display. In the last four measures, the sixteenth-note-triplets become thirty-second-note triplets. 
- Variation 8: While Paganini’s caprice has straight eighth-note-chords that are played in a bold and gutsy manner, Liszt distributes the chords and makes subdivisions between the two hands, which makes the section more animated than the original caprice.

- Variation 9: Liszt preserves the pizzicato effect of the caprice. He adds Alberti basslike accompaniment in the left hand, which also works as an outline of the theme. This variation also features large skips.

- Variation 10: The trill accompaniment in the left hand works as an open fifth (A and E) pedal tone for the A section. The middle notes are moving by step (E-D-C-B). Interestingly, Liszt wrote a free trill for the A section, and a written-out trill for the B section.

- Variation 11 - Coda: Compared to the previous variations, Variation 11 with coda seems different from Paganini’s caprice. Liszt preserved only some fragments and ideas of the caprice, but did not transpose them in the same manner as he did in prior variations. The theme is split between two hands. When the theme is played in one hand, the other hand has thirty-second-note runs. In the Coda, the theme in the left hand becomes thirty-second notes. The arpeggiated runs near the end are very similar to the caprice but Liszt changes a few notes for a slightly different harmony. Liszt throws an F-natural in the last A major arpeggio run to give it a hint of harmonic twist. Furthermore, a chromatic swell before the final cadence adds the intensity of a dramatic ending.

\section{PEDAGOGICAL SUGGESTIONS}

\section{$\underline{3.1 \text { Level of Difficulty }}$}

The works of Liszt can be categorized into early/middle and late. His late works are very different than his earlier ones. If one compares the two, the style of his music changes 
drastically. The later works are technically less difficult, focusing on forward-looking technical devices, such as Impressionism or atonality. Regardless, the piano works of Liszt are generally advanced and difficult.

The Paganini Etudes were written in the early/middle stage of his musical career, and since it is nearly a transcribed work of Paganini's Violin Caprice, the level of difficulty of this piece is fairly advanced. Even the theme is more difficult than the other four compositions because of its wide intervals of arpeggiated chords such as tenths, elevenths and thirteenths in both hands. This etude also features many acrobatic passages and rapid runs in octaves, which suggests it is suitable for at least college-level advanced performers.

\subsection{Performance and Pedagogical Guidelines}

This section of the paper includes performing suggestions of the author. Therefore, the first person will be used.

The sixth Paganini Etudes requires a combination of multiple pianism, yet there are five major technical aspects: wide intervals, acrobatic passages, octave runs, tricky fingerings, and long trills.

\section{WIDE INTERVALS: Theme and Variation 1}

Imagine that you are giving a recital and start playing big arpeggiated chords of the theme, but keep missing the top notes. This would be every pianist's nightmare! Both hands have big chords and need to turn if necessary. If one has big hands like Rachmaninoff, it would not be a problem. However, these wide chords could be challenging for those with average-sized hands. 
There are few ways to solve this problem. A flexible wrist is the first solution. Start the roll with a low wrist position then raise the wrist as it moves up. It will ease the muscles and make it easier to find the chords. But if your hands are small and you still miss some notes, another solution is to take one note from one hand with the other hand, whichever is stronger. In my case, it is easier to play the bottom three notes with my left hand and take the $\mathrm{C}$ in the left hand with my right hand. Thus, A-E-A with my left hand and C-E-A-C-A with 1-2-4(5)-1-4(5) fingering (See Figure 2.4). However, at the B section of the Theme, some measures do not work since the interval between the left hand and the right hands is a tenth (See Figure 2.5). Finding the best fingering to fit your hand is the best suggestion for those measures. Resume the above fingering when it is applicable.

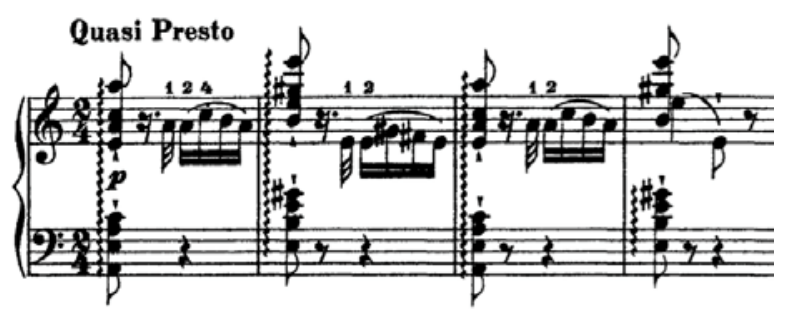

[Figure 2.4] A section of the Theme

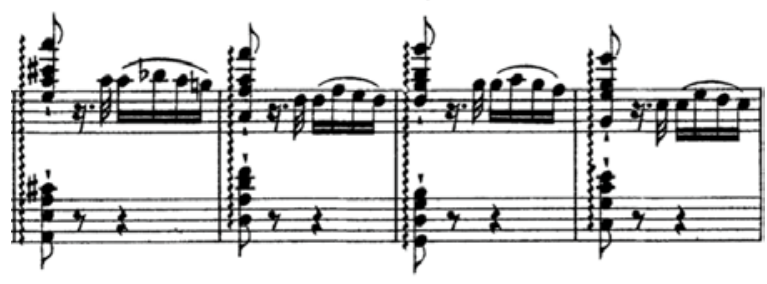

[Figure 2.5] B section of the Theme

Variation 1 has grace notes before every downbeat. The interval between the grace notes and the downbeat are a tenth apart. This passage also requires a flexible wrist and a stretch of the hand. Suggested fingerings for the grace notes are 1-2(or 3)-5 fingering with all white notes, and 1-3(or 4)-5 fingering with a black note (G\#) (Figure 2.6). 


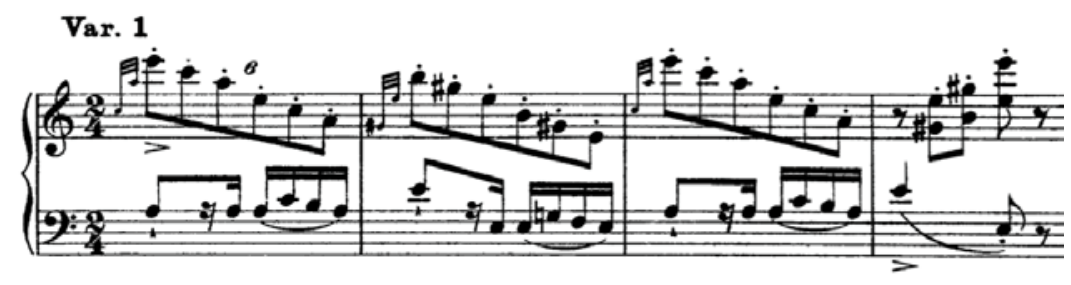

[Figure 2.6] Variation 1

\section{ACROBATIC PASSAGES:}

Variation 5, Variation 11 (especially 12 measures after), and Coda

Practicing Variation 5 can be tricky. One might question whether to play the sixteenth notes in the interval of fifths/sixths with both hands or with only the right hand. Either way could work yet each has pros and cons. If one plays the first two with right hand and the last two with left hand, the right hand gets more time to travel down to the triplet figure. However, when the right hand moves down and cues to play the triplet, it partially blocks its way for the left hand to move down. After the triplet, the left hand has to keep moving up and down which, in result, could be more difficult. Another advantage of playing this way is that one can play the slur more easily, but it can also be executed well with the help of a sustaining pedal. If one plays it with the right hand only, it could be overwhelming at first because it constantly has to move up and down. Yet if one follows the drop and rebound technique, the passage is comfortably playable with one hand indeed (see Figure 2.7). The rebound is not necessarily an upward position. It should be the direction where the next notes are.

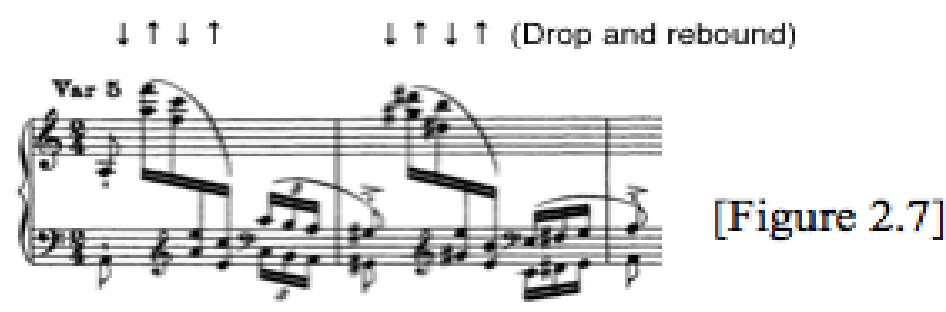


Variation 11 near the coda (12 bars after) is painfully difficult if one does not use the drop and rebound technique properly (Figure 2.8). I also find it helpful to move my entire upper body to the direction of the notes with relaxed muscles. Playing this acrobatic passage with a fixed body position is not only difficult but also could hurt your forearms.

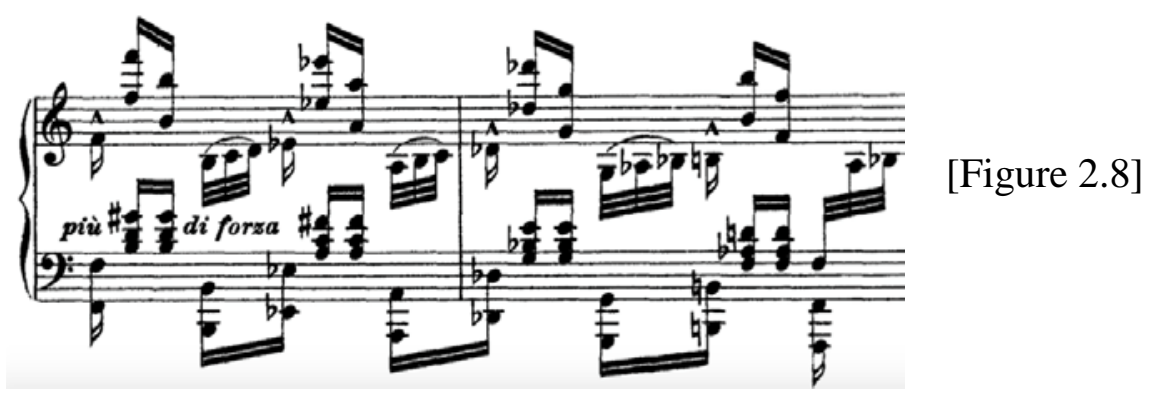

The coda features arpeggiated passage works in the right hand while the theme is in the left hand. These arpeggios should sound flowing and smooth, and should not overpower. Whenever there are flowing arpeggios like this, make sure to practice in blocked chord and figure out the most natural fingerings for your hand. It is not necessary to connect them with fingers since the sustaining pedal will do the job for you. It is helpful to move your hand position quickly. There are many possible fingerings for the A major arpeggios near the end. The typical fingerings for playing arpeggios is 1-2-3-5-3-2-1: thus, 1-2-3-1-2-3-1-2-3-1-2-3-5-3... and so on. However, I think this fingering does not feel comfortable for a couple of reasons. First, the arpeggiated run is too long - four octaves, to play with the first three fingers. The center of gravity is on the first three fingers, which feels uncomfortable and unstable. Secondly, managing the leap after playing first A-C\#-E could be tricky. It could affect the accuracy of the notes. Therefore, I suggest the following fingering: 121241241241414214214213 (right hand). 


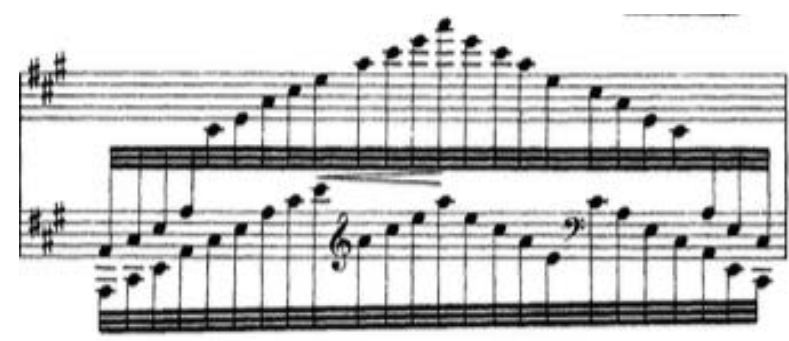

[Figure 2.9]

This fingering leads to a more comfortable hand position and feels more stable. Also the leap from $\mathrm{C \#}$ and $\mathrm{E}$ is less wide than $\mathrm{E}$ and $\mathrm{A}$, thus managing the leap is easier.

\section{OCTAVE RUNS:}

Variations 4, 6, and 11

Playing long octave runs is one of the most challenging techniques in piano playing. However, it can be playable with three rules in mind: 1) low wrist position for runs on white keys, 2) high wrist position for chromatic runs, and 3) using thumb and fourth finger on black keys for chromatic runs.

Variations 4 and 11 have octave runs that move chromatically. Using thumb and fifth finger on white keys, and thumb and fourth finger on black keys instead of playing all with thumb and fifth fingers will ease the tension on forearms and increase the accuracy of playing.

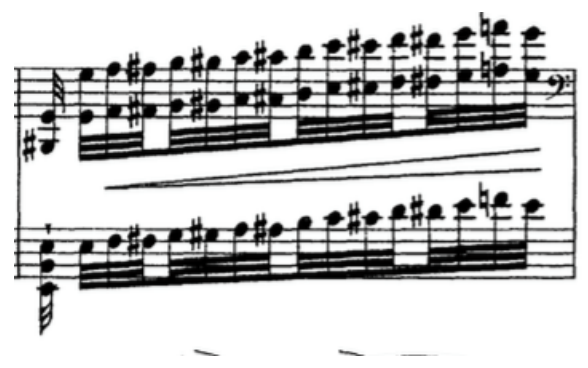

[Figure 2.10] Excerpt from Variation 11 
Another tip is to have a high wrist position which will help you to relax muscles and enables those octave runs to bounce.

Variation 6 displays a combination of thirds and octaves. Unlike variation 4 where it requires a high wrist position, Variation 6 requires a low wrist position mostly for runs on white keys. Also, putting more weight on the thirds and letting the thumb tag along could be helpful (Figure 2.11).

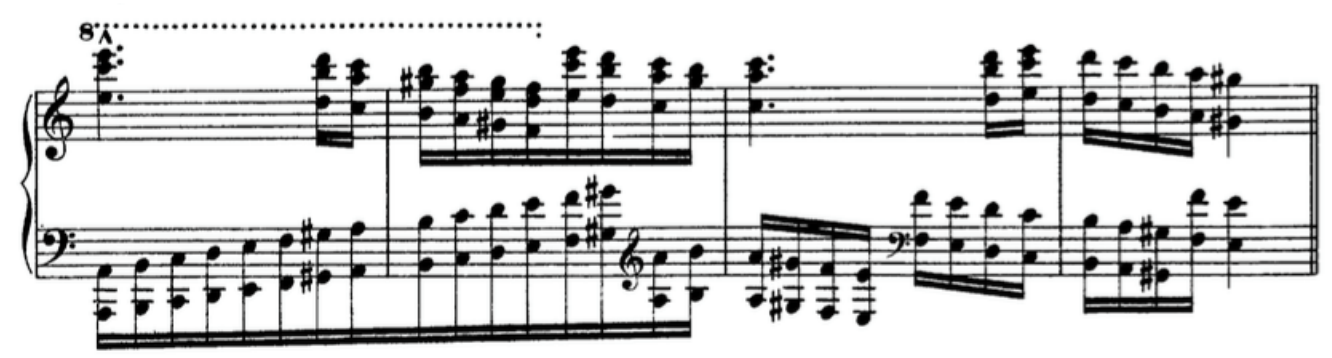

[Figure 2.11

\section{TRICKY FINGERINGS:}

Variations 6, 7, and 9

Every pianist will agree that efficient fingerings make playing tremendously easier in certain sections. Variation 6, 7 and 9 are great examples of this. As mentioned above, Variation 6 features runs in thirds and octaves. There are many possible fingerings to play thirds, typically 35 and 2-4 and 1-3 or 1-4 and 2-3 in particular circumstances. However, the tempo of this piece does not comply with these fingerings. It will result in a "finger twister!" To play the thirds in the left hand, many editors suggest using 2 and 4 all the way. This will work if your fingers bounce off keyboard as if you are dribbling a basketball.

In Variation 7, the quarter notes can be held with finger substitution technique, which is very common in organ playing. It involves replaying one finger which is depressing a key with 
another finger. Thus, in Variation 7, as soon as you play C in both hands, you may substitute your fingers with $5(\mathrm{RH})$ and $1(\mathrm{LH})$ to play the chord that follows. In this way, you may find it is much secure to play the following triplets.

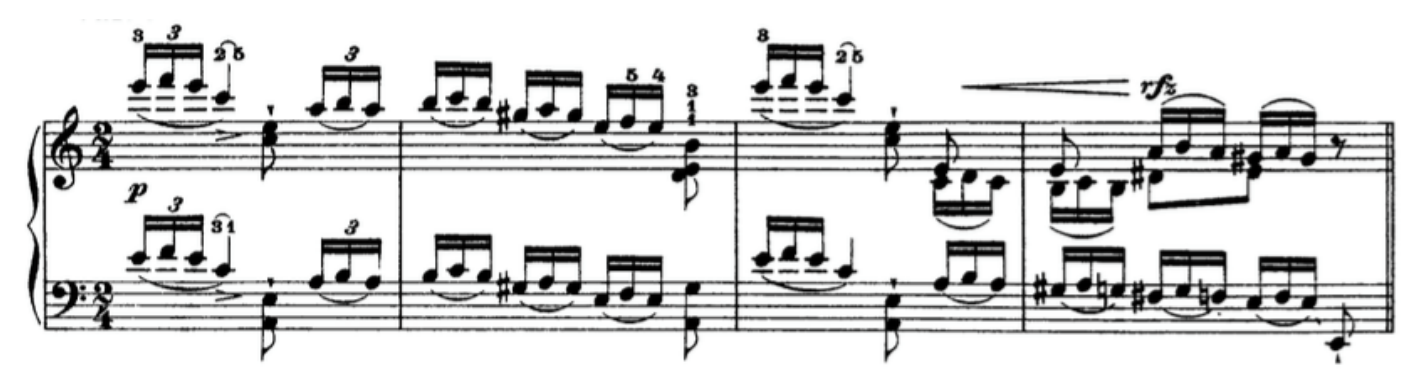

[Figure 2.12] Variation 7

\section{LONG TRILL: \\ Variation 10}

This is one of the most difficult passages in this piece, not only because the trill is long but because there are notes going underneath while the trill is going. One easy trick is to play the bottom notes and let go of them as soon as you play with touches of sustaining pedal. This will give you more freedom to play the trill. However, performer must be careful not to play them too loudly. It needs to be shimmering underneath the melody. 


\section{CHAPTER THREE: \\ VARIATIONS ON A THEME BY PAGANINI, OP. 35 (1862-63) BY JOHANNES BRAHMS}

\section{BACKGROUND}

The keyboard variation is probably the genre that has been used most consistently from the beginning of keyboard music through the centuries. In the nineteenth century however, its popularity decreased because the interest in the freedom and programmatic possibilities of the character piece tended to push the use of the variation to a peripheral position in the catalogue of many composers. ${ }^{6}$ Yet Brahms' sets of variations show his masterful ability in a milieu that seems totally comfortable.

Brahms wrote six sets of variations for solo piano. Five of these have opus numbers, and a sixth set, seven variations written on an original theme in $d$, is a transcription of the slow movement of the first sextet, Op. 18. Except for Op. 21, No.1 (1857), a set of eleven variations that is based on an original theme, Brahms borrowed pre-existing thematic material as the basis for his variations. The Op. 9 (1854) is a set of sixteen variations based on the fourth piece in Schumann’s Bunte Blätter (Op. 99); the Op. 21, No. 2 (1853), uses a Hungarian song as the basis for thirteen variations; the Op. 24 (1861) takes a theme for the first suite of Handel's Suites de pieces de clavecin (1733) as the source of twenty-five variations and an extensive fugue; the Op. 35 (1862-63) is based on the twenty-fourth caprice of Paganini. ${ }^{7}$

The Paganini variations were published in 1866, and were the last set of variations Brahms wrote for piano solo. They consist of two volumes, both in the original key of A minor.

\footnotetext{
${ }^{6}$ Steward Gordon, A History of Keyboard Literature: Music for the Piano and its Forerunners (Belmont, CA: Schirmer, 1996), 339.

${ }^{7}$ Ibid.
} 
These two books share the same formal layout, each containing the theme, fourteen variations, and a large three-part coda connected to the fourteenth variation. However, the characters of these two sets are quite different. The first volume is technically more challenging, more restless and formidable, while the second volume is more pianistic, more sensitive, and musically more difficult. ${ }^{8}$ Regardless, both volumes have great intensity and display the typical virtuosity and bravura style of nineteenth-century writing.

Although Op. 35 has the original title of "Variations” on a Theme by Paganini, Brahms gave the piece another name as "Stüdien für Pianoforte" (Etudes for Pianoforte) in the manuscript which suggests the technical challenges of the work. This etude-character is taken directly from the original intent of Paganini’s caprice — while Paganini developed a particular violin technique in each variation, Brahms deals with a particular keyboard technique. However, Brahms’ treatment of keyboard writing is entirely different from the previously discussed variations of Liszt. Liszt's Paganini variations are transcriptions of the entire set of Paganini’s theme and variations, transliterating violin writing to the keyboard in order to produce the same effects. Brahms, on the other hand, does not transcribe the original material, but instead treats each variation as a different technical exercise that is typical of his own writing. These variations are only related to the original violin line in their melodic motives. ${ }^{9}$ Some of the technical challenges in this piece include double sixths, double thirds, and octaves filled in at the third, resulting in the thick texture sound of Brahms; skips combined with trills; large leaps of a tenth or more; octave glissandi; broken octaves. In addition, Op. 35 displays compositional and

\footnotetext{
${ }^{8}$ Zhou, 57.

${ }^{9}$ Benita W. Tse, "Piano Variations Inspired by Paganini's Twenty-Fourth Caprice from Op. 1” (D.M.A. diss., University of Cincinnati, 1992), 87-88.
} 
rhythmic complexity such as imitation, double counterpoint, canonic writing, cross-rhythm, the retention of the same pulsation in a new note value, and so on. Both books of Op. 35 finish with an extended coda which clearly indicates that these variations are meant for public performance.

\section{GENERAL ANALYSIS}

Although Brahms did not write any set of etudes in the same manner of Chopin's two sets of etudes, he definitely composed Op. 35 in the spirit of etudes. A typical etude would have one or few technical exercises within a piece, and usually brief in length. Brahms treats each variation as a short etude and extends its virtuosity by adding a coda which is connected to the last variation.

\section{$\underline{2.1 \mathrm{Key}, \text { Structural, and Stylistic Designs }}$}

Brahms' approach to the variation follows the pattern of the traditional theme and variation form. Variations typically trace the harmonic scheme and the phrase structure of the original theme to full extent. The first volume is in A minor except for Variations 11 and 12 which are in the parallel major key. The second volume is also mostly in A minor except for Variation 4 in A major, and 12 in F major. Even though these two volumes are written in the key of A minor, each of them approaches different harmonic and rhythmic characteristics. In comparison of the two books, Tovey writes:

"The second set may be said, in a sense, to begin where the first left off, though it is also a perfectly complete and independent work. But it begins with a harmonic freedom much like that which was so startling in the fourteenth variation of the first set; and it plunges at once into a most impassioned storm, which is the more effective from the fact that the theme is stated very quietly and delicately. Brahms thus makes his second set intelligible from two points of view-as a further development from the first set, and as an independent work, opening on the opposite system to that of the first set, whereas the first set opens broadly with a large block of simple and severe variations to pave the way for more elaborate and impassioned; the second set opens dramatically 
with some of its most free and impassioned, designed to tone down, as the passion exhausted itself, into simpler variations that embody the exact harmonies of the theme." 10

In terms of the style of each variation, Brahms not only used etude-like style but also incorporated popular style. For example, the fourth variation in the second volume is in the style of a Viennese waltz, and the eleventh variation in the first book sounds as if it is played on a music box because of the higher register. These popular style variations are technically easier than other variations in the sets, and provide a little bit of a break to catch a breath both for performer and listener.

\subsection{Meter, Rhythm, and Tempo Relationship}

The common meters that Brahms used in this piece are 2/4, as in the theme, and 6/8. As Brahms' favorite rhythmic device, two-against-three or three-against-four are common in this piece. Rhythmically the most challenging variation would be Variation 7 in the second volume which has a polymeter (2/4 in the right hand and 3/8 in the left hand). The right hand has four eighth notes while the left hand has the outline of three eighth notes with triplet undercurrent. This can be extremely challenging. More detail will be discussed later in this chapter. Variation 3 in Volume I is also tricky. Brahms placed metric accents (continuous sforzandi in a contour of sixteenth-note figures) in order to reinforce the meter. But one can easily be misguided and think in triplets, which Brahms did not write. The latter part of this chapter provides some useful practice tips for this variation as well.

\footnotetext{
${ }^{10}$ Donald F. Tovey, Essays in Musical Analysis: Chamber Music (Mineola, NY: Dover Publications, 2015), 180.
} 
Brahms also ingeniously makes tempo changes by retaining the same pulsation in a new note value. This tempo relationship between the variations is closely related throughout the sets. For example, the eighth note value in Variation 8 becomes a quarter note value in Variation 9 (Book I). Then, the quarter note value in Variation 9 becomes the eighth note value (Figure 3.1).
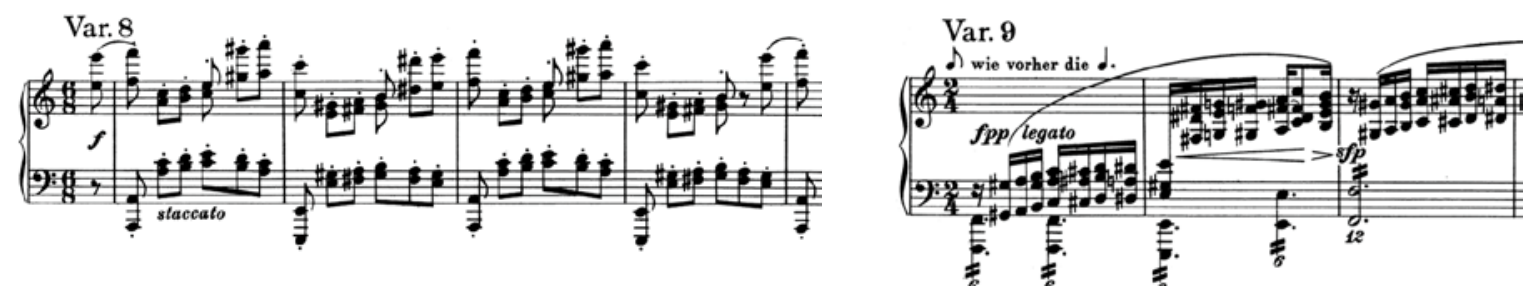

[Figure 3.1]

Another instance can be found in Variations 11 and 12 (Book I) which are andante and dolce, and the following Variation 13 is vivace in a scherzo style. Brahms used the same technique to make this tempo change — the pulse stays the same but the note value changes.
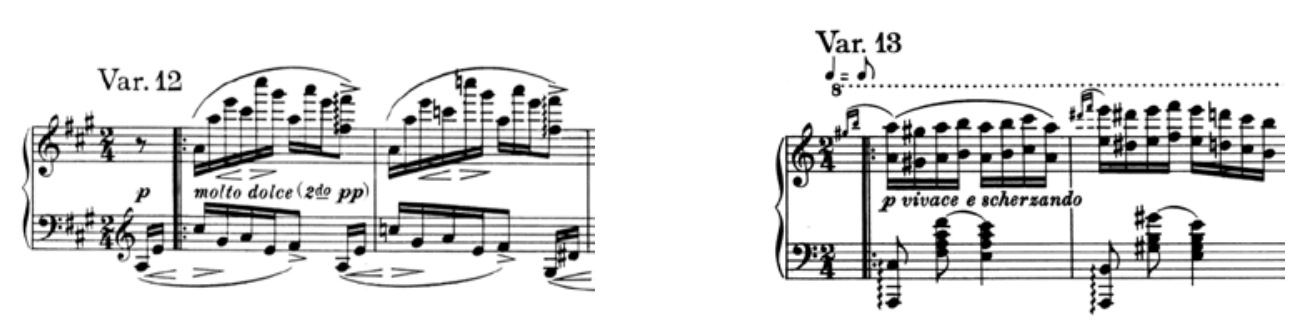

[Figure 3.2]

\section{$\underline{2.3 \text { Texture }}$}

Since Brahms aimed for different technical focuses in writing this piece, the texture changes throughout the piece. Brahms' music tends to have thick texture, and this is not an exception. The chords made up of thirds, sixths, and sweeping broken octaves result in heavy texture in the piece in general. However, the texture of the theme is rather transparent and sticks 
to its originality. Variation 3 in volume I, and Variations 6 and 14 in volume II are also very thin and almost scherzo-like.

\section{PEDAGOGICAL SUGGESTIONS}

\subsection{Level of Difficulty}

Most of the compositions that are based on the Paganini theme are fairly difficult. As the original caprice for violin by Paganini was written to showcase the technical dexterity of a performer, Brahms also composed this bravura piece with demanding techniques. Some believe the first volume is technically more difficult than the second set. However, the author believes while the first set requires good techniques, the second set also requires more pianism and musicality. Also, Variation 7 in the second set is extremely complex rhythmically. Therefore, it is difficult to jump to a conclusion of which set is more challenging. Both sets require the dexterity and musicality of a performer.

In general, these two sets are suitable for college-level advanced students with good technique if one plays the entire set for public performance. However, the author believes that this piece can be performed by a good intermediate to advanced student if he or she selects some variations which are appropriate for his/her proficiency. It is debatable. However, the author believes if one carefully studies the flow of the music and understands the continuity between the variations, it could be done effectively.

\section{$\underline{3.2 \text { Performance Option }}$}

To perform Brahms’ variations, there are few options one can choose. The two books can be performed together back to back or one can choose only one volume of the two since playing 
one set after the other could be somewhat redundant for listeners. Another option is to select variations from each volume as the author has mentioned above. It is not inappropriate to experiment with this option since it had been done back in the nineteenth century.

The first performance of these variations was by Herr Barth on March 1, 1880 at the Monday Popular Concerts. Instead of playing the two sets in their entirety, Brahms gave his approval to combine a selection of variations from both books, and arranged them in a sequence to produce the best effect. The selection which Brahms suggested was as follows:

Theme

Book I: Variations 1, 3, 5, and 9;

Book II: Variations 6, 8, and 12;

Book I: Variations 10, 11, 4, 13, and 14 (finale) finale ${ }^{11}$

Although the author believes that it is the best to perform the piece as the composer wrote, choosing variations from the two books can be useful for pedagogical reasons. Some variations are more difficult and some are easier. Also, some variations are physically impossible to execute perfectly if one has small hands. Therefore, a student can choose appropriate variations for his proficiency level and/or for physical limitation.

\section{$\underline{3.3 \text { Performance and Pedagogical Guidelines }}$}

In performing Brahms’ Paganini variations, the author will discuss some helpful practice suggestions. This paper will not mention every single variation. Rather, it will provide the general ideas of how the piece should be played, practice tips for selected variations which are believed to be the most difficult ones, and the stylistic and technical guidelines including pedaling and fingering.

\footnotetext{
${ }^{11}$ Edwin Evans, Handbook to the Pianoforte Works of Johannes Brahms (New York: Lenox Hill, 1970$), 167$.
} 


\section{Book I:}

- Variations 1 \& 2: Variation 2 is an inversion of Variation 1 . These first two variations mainly consist of thirds and sixths. One of the challenges is obviously to execute the thirds cleanly. The standard fingering for playing third trill-like figures might be alternating 5-3-1 and 4-2. If one is weak with 3-1/4-2 trill, another efficient fingering for the thirds can be 5-4-1/3-2. Pedal should be held per measure.

- Variation 3: The point in this variation is the pertinacity of the sforzando reiterations (Figure 3.3). The emphasis is only visibly indicated when falling upon single notes. However in reality, it is to be observed throughout the variation ${ }^{12}$. This variation requires hand crossing and judicious phrasing. The player should be aware of the meter and understand where the beat is. One can easily think in triplet and lose the placement of every downbeat.

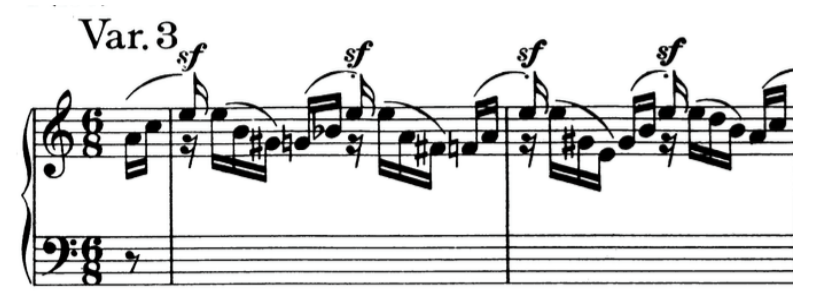

[Figure 3.3]

- Variation 4: It is one of the hardest variations which consists of chords with trills. One should play the chords, then let go of the bottom two notes. Playing large arpeggios depends upon facility in change of hand position. Therefore, good fingering will make this easier to play.

- Variation 9: The stationary octaves should be played lightly as accompaniment. Vars. 9 and 10 should be connected smoothly with careful ritardando and diminuendo.

- Variation 11: Variation 11 is deceitfully difficult. It is the slow variation that mimics the sound of a music box. The melody is the top line in both hands, and the accompaniment is

\footnotetext{
${ }^{12}$ Evans, 153.
} 
also in both hands moving in opposite direction. Intellectually, it is very simple yet kinetically it is extremely confusing and challenging to memorize for some pianists. It is similar to drawing a circle in one hand and a triangle in another hand. At first, practice extra slowly for your brain and fingers to process until both intellectual and kinetic memories cooperate.

- Variation 13: This variation requires the octave glissando. Use your thumb for the glissando and let the fifth finger tag along. For the fast octave passages in the right hand, use a low wrist position and play lightly with bouncing flexible wrists.

- Variation 14: It features broken octaves and arpeggios. One should practice in blocked chords, and avoid connecting them only by finger. Rather, change the hand positions quickly.

\section{Book II:}

- Variation 1: The performer should decide which part to emphasize between the octaves and the thirds. It could be either way. Bringing out the octaves may emphasize the musicality while the thirds may compliment the pianistic technique. But no matter what, make one part distinguishable from the other part. Careful fingerings and quick changes of hand position will make it easier to play the thirds.

- Variation 3 should use very little or no pedal.

- Variation 4 has the spirit of a Viennese waltz. It can be a graceful waltz or a more outgoing waltz. The melody should be articulated. The challenging aspects are large leaps in the left hand. Pedal should be held per measure.

- Variation 7 is notoriously known as the hardest variation in the set in terms of rhythmic complexity. It is polymeter- 2/4 and 6/8; and because of this uneven distribution (four against nine) of the notes between the right and the left hands, there are two views of 
practicing this deadly variation. One way to practice is play each hand alternately at exactly the same tempo, and when each hand has acquired a certain habit, put them together. This might work for some people. But the author believes that if one is under pressure, in a recital setting for example, it could go out of the window with this type of practice, because one is depending a lot on muscle memory. Kinetic memory is one of the four major types (visual, analytic, aural, and kinetic) of memorization, and it is very helpful in some cases with no doubts. However, playing this entire variation by only muscle memory could jeopardize the whole performance. The other way to practice is to mathematically calculate the duration of each note, and know where each note should be placed. One should figure out a common denominator for both meters, and practice the smallest note value slowly in one hand. Then, figure out the placement of the opposite hand. This variation mainly consists of four against nine. The common denominator of four and nine is thirty-six. Therefore, each eighth note in the right hand gets 9 , and each sixteenth note triplet in the left hand gets 4 . When lay out this number, it should look as below (Figure 3.4):

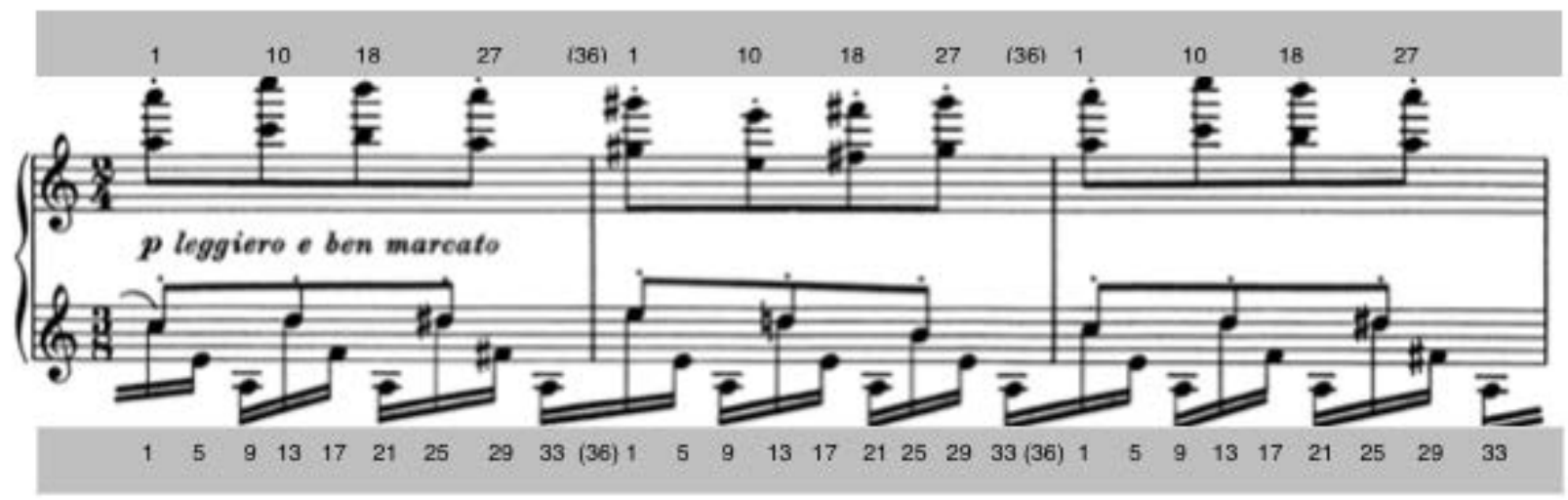

[Figure 3.4] 
In other words, if one plays these notes while he counts from one to thirty six, he just played all the notes exactly where they should be. In reality, it is impossible to count and play when it is up to tempo. However, this definitely gives a helpful guideline for a performer to figure out the placement of the two hands.

- Variation 10: exhibits a skillful use of arpeggio-forms; ${ }^{13}$ bold monotonous character; play the octaves then change the hand position quickly to find the broken chord, have good fingerings.

- Variation 11: technical objective, practice in dotted rhythms; parallel fingering

- Variation 12: only variation of either book for which another tonic is adopted (F major); romantic cantabile style; sensible, may use some rubato.

- Variation 13: requires efficient fingerings for descending third and a single note combination to sound smoothly legato. Figure 3.5 shows Eusebius Mandyczewski’s fingering suggestion. Author also suggests 53-1-42-1-53-1-42-1-53-2-53-1-52-1-52-1.



\footnotetext{
13 Evans, 165.
} 
- Variation 14 - Coda: The challenging aspect in this section is to build the intensity and excitement to the acrobatic ending. As Brahms uses metric modulation quite often throughout the work, the coda is not an exception. $2 / 8$ becomes $2 / 4$, then $6 / 8$, and at the end, two meters are used (2/4 and 6/8) while the main pulse stays the same. When a group of triplets appears at the meter change from $2 / 8$ to $2 / 4$, be cautious thinking in triplet due to tendency of rushing and losing the pulse. For the passage where the same notes are played in octaves, using circling wrist motion makes it easier to play. 


\section{CHAPTER FOUR: \\ RHAPSODY ON A THEME BY PAGANINI, OP. 43 (1934) BY SERGEI RACHMANINOFF}

\section{BACKGROUND}

The Paganini theme was not only borrowed for solo piano works but also for concertante works. Rhapsody on a Theme by Paganini for piano and orchestra, Opus 43 by Sergei Rachmaninoff (1873-1943), and Paganini Variations by Witold Lutosławski (1913-1994), for example, are among the major works for piano and orchestra which are based on the Paganini tune. Rachmaninoff's Rhapsody is written in the style of his piano concertos, yet in the form of theme and variations. The work was written at Villa Senar in Switzerland from July 3 to August 18, 1934. Rachmaninoff himself, a noted interpreter of his own works, played the solo piano part at the piece’s premiere at the Lyric Opera House in Baltimore, Maryland, on November 7, 1934 with the Philadelphia Orchestra, conducted by Leopold Stokowski. The theme Rachmaninoff used in the Rhapsody had of course already attracted many composers before him as variation material, most notably, as Rachmaninoff himself was aware, Liszt and Brahms, but after him, as though spurred by the Rhapsody’s triumphant proof that this vein of musical ore was by no means exhausted. Many others besides have taken up the challenge, beginning with Lutoslawski in 1941, and including practitioners of popular music as diverse as John Dankworth and Andrew Lloyd Webber. ${ }^{14}$

The enchanting eighteenth variation is by far the most well-known, and it is often included on classical music compilations as an excerpt. The melody of the eighteenth variation is based on an inversion of the melody of Paganini’s theme.

\footnotetext{
${ }^{14}$ Barrie Martyn, Rachmanioff: Composer, Pianist, Conductor (New York: Routledge, 2016), 326.
} 
Around the time when the rhapsody was composed, a new musical movement was spreading. Schoenberg introduced the concept of abandonment of tonality in 1908, and developed a systematic way to write serial music in the early 1920s. Along with Berg and Webern, the practice of serial music became the norm for the next few decades. Rachmaninoff, however, was greatly influence by Chopin, Liszt, and Tchaikovsky, and followed the traditional style of the Romantic Period.

Rhapsody on a Theme by Paganini is often called Rachmaninoff's fifth piano concerto because it is symphonic and rhapsodic, expanding its musical means to the piano and the orchestra with a variety of tone colors. Since the harmonic progression and phrase structure are freer, he utilizes motives of the theme rigorously to maintain continuity and comprehensibility. In that sense, the work bears a motivic development - characteristic of a symphony or concerto. It is a hybrid of a classical theme and variations and a musical drama, creating a narrative on the original theme. The traditional form of theme and variations now arrives at a new frontier. ${ }^{15}$

\section{GENERAL ANALYSIS}

Rachmaninoff gave the piece the title "Rhapsody" instead of "Variations" although he indicates each musical section as “variation”. In fact, Rachmaninoff named it "Symphonic Variations on a Theme of Paganini” at first. He soon abandoned the original title, and modified it as “Fantasia for Piano and Orchestra in the Form of Variations on a Theme of Paganini.” But he eventually referred the work as a rhapsody at the end. ${ }^{16}$

\footnotetext{
${ }^{15}$ Zhou, 73.

16 Martyn, 326.
} 
This piece definitely has features of theme and variations because each variation is derived from material from the theme. Comparing it with the variations of Liszt and Brahms however, Rachmaninoff has a compositional style and formal design that are significantly different. For the variations of Liszt and Brahms, each variation is independent enough to rearrange the order. Rachmaninoff, on the other hand, often connects one variation to the next variation. Another interesting aspect about Op. 43 is that Rachmaninoff adds fermatas at three significant places. These appear at the end of Variations 10, 15, and 18. These fermatas support the sectional design of the work which will be discussed later in this chapter.

\subsection{Structural and Stylistic Designs}

Rachmaninoff did not write Opus 43 in movements, yet it has four distinctive sections which can be analyzed as movements in a similar manner as Liszt's B minor sonata. The structural design in general could be analyzed as following:

- Section/movement I: Introduction-Variation X

- Section/movement II: Variation XI-Variation XV

- Section/movement III: Variation XVI-Variation XVIII

- Section/movement IV: Variation XIX_-Variation XXIV

There might be some pianists who would analyze this piece in a different way, but the fermatas Rachmaninoff himself marked at those three specific places are clear evidence that he was thinking in movements when he composed this work. The number of the movement/section of this piece is also the same as in a typical symphony or concerto. In addition, the choice of form and style is very similar to a symphony. 
Section I is the longest of the four, and begins with an introduction. Interestingly, the theme appears after Variation 1 which is very unusual. Section II starts in a serene mood and leads to the expressive Variation 12 in a minuet style. Then, the mood suddenly changes at Variation 13. The section ends with a playful scherzando cadenza-like piano solo. Section III is a slow movement with the most well-known eighteenth variation. Section IV is a fast movement with driving energy and pianism.

\section{$\underline{2.2 \text { Harmonic Idioms and Tonality }}$}

The music of Rachmaninoff usually shows extreme Romanticism. Opus 43 is not an exception. The basic harmonic progression of the theme is quite conventional at the beginning, but Rachmaninoff added extra decoration in sound color with chromaticism.

The tonal areas he chose are also a little more adventurous than the previous two composers mentioned above. While the works of Liszt and Brahms stay in a tonic key most of time, Rachmaninoff changes its key area more often as the piece proceeds. These key changes mostly happen in the middle, and the outer two parts are relatively stable in A minor. The beginning through Variation 11 is in A minor. From variation 12 through variation18, multiple tonal shifts happen: Vars. 12-13 in D minor, Var. 14 in F major, Vars. 16-17in B-flat minor, and Var. 18 in D-flat major. The A minor tonal center comes back after the eighteenth variation and stays until the end. These tonal centers are somewhat correspondent with the sections analyzed above: Section I in A minor; Section II in D minor and F major (parallel keys); Section III in Bflat minor and D-flat major (parallel keys); Section IV in A minor. 


\subsection{Theme and Other Melodic Figures}

The A minor Paganini theme invades the work of course, but there are two other substantial melodic figures in this work. The first one is Dies Irae, the plainchant melody from the requiem mass, famously brought into the concert hall by Hector Berlioz a hundred years earlier in his Symphonie fantastique and a much-used theme in its own right. This melody has been used as a theme or musical quotation in many classical compositions.

This quotation first appears in Variation 7 in the piano while the orchestra plays the Paganini thematic material. Later in Variation 10, it comes back in augmented version but quickly transits to the Paganini material (See figure 4.1).
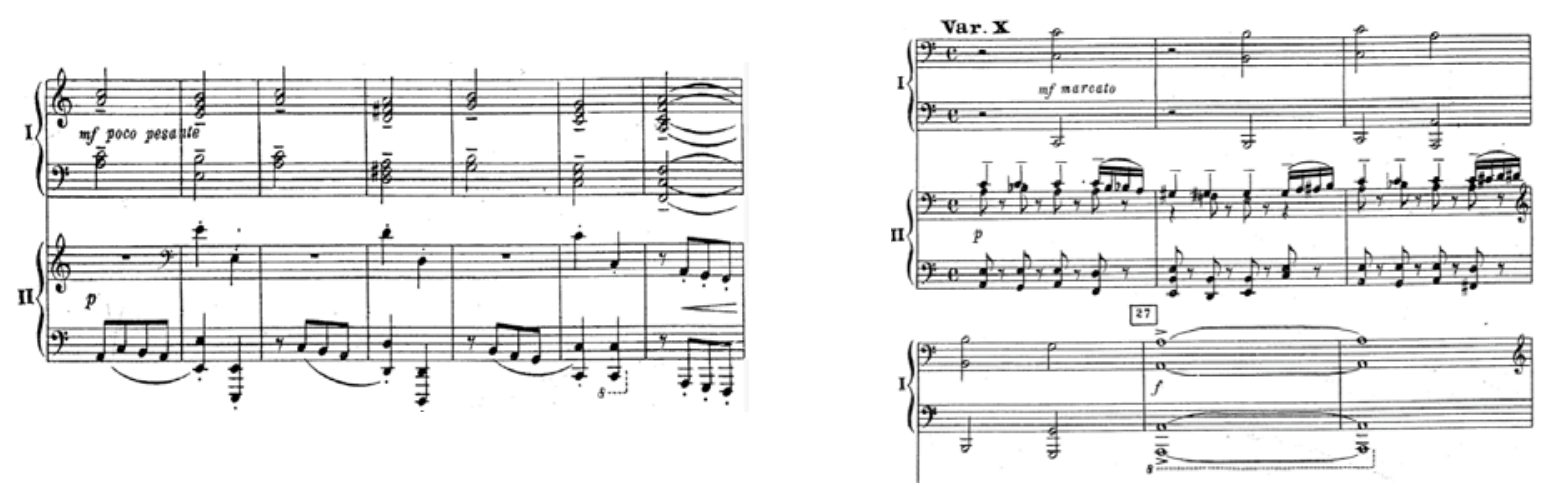

[Figure 4.1] Dies Irae in Variations 7 and 10

The second important melody in this work appears in the eighteenth variation. One can hardly associate this beautiful melody with the Paganini theme. They have totally different moods and characteristics. However, it is an inverted form of the original Paganini theme! Figure 4.2 shows the original theme in A minor and the inverted theme in A major. Rachmaninoff then transcribed the melody in D-flat major, and also changed the meter from 2/4 to 3/4. 


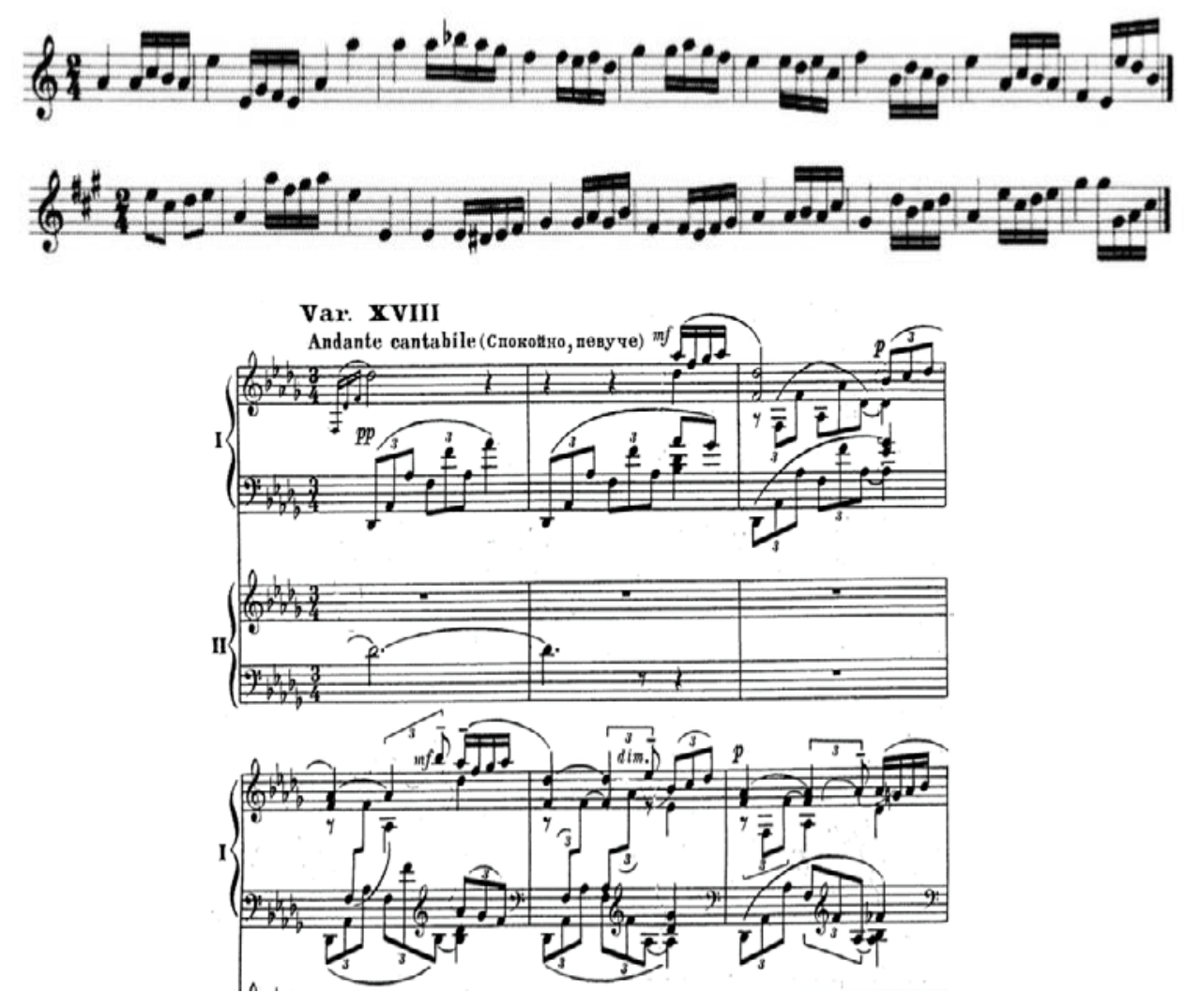

[Figure 4.2] Paganini theme and its inversion \& Variation 18

The eighteenth variation is the pinnacle of the work. The inverted melodic contour along with Rachmaninoff's unlimited musical imagination morphs into a sophisticated and full-bodied lyrical statement. This variation is charged with a masterful compositional skill that ultimately provides an architectural build-up toward an emotionally exuberant peak. ${ }^{17}$ Abram Chasins writes “...It seemed to me that there was not very much left to do with this theme, that the possibilities had been exhausted, but you have conclusively proven the contrary by this latest opus." 18

\footnotetext{
17 Zhou, 112.

${ }^{18}$ Sergei Bertensson and Jay Leyda, Rachmaninoff (New York: New York University Press, 1956), 309.
} 


\section{PEDAGOGICAL SUGGESTIONS}

\subsection{Level of Difficulty}

Rachmaninoff was a virtuoso pianist whose playing was so breathtaking that any of his contemporaries were said to have proclaimed him the greatest of his generation. As a result, his piano music tends to take for granted complete command of the instrument. Compared to the previous two etude-like compositions, the beginning of the rhapsody is distinctively simpler. However, it gets more elaborated as it proceeds. Opus 43 is a challenging piece not only for the playing technique but also for the collaboration with orchestra or second piano. In certain ways, opus 43 is the most difficult work among the five selected pieces.

\subsection{Performance and Pedagogical Guidelines}

From the introduction to Variation 5, the main concerns in performing are clarity and evenness of notes. The overall texture is rather transparent in this section. For Variations 2 and 4, the use of sustaining pedal should be limited especially for the first half of each of the variations. The following is a list of practice suggestions.

- Variation 2: Since the Paganini theme has repetitive nature, it is a performer's role to keep the music interesting. By a quick dynamic shift, the music can come alive: play the first four measures in $m f$, then the next four measures in $p$. The grace note has to be very quick and precise as if you are playing the grace note and the principle note together.

- Variation 4: Even sixteenth notes can be accomplished through rhythmic practice.

- Variation 5: A key factor of this variation is the correspondence between piano solo and orchestra/second piano. This interesting dialogue between the solo and tutti because they 
hardly play at the same beat. Listen to each other carefully since the two must have the same tempo and pulsation.

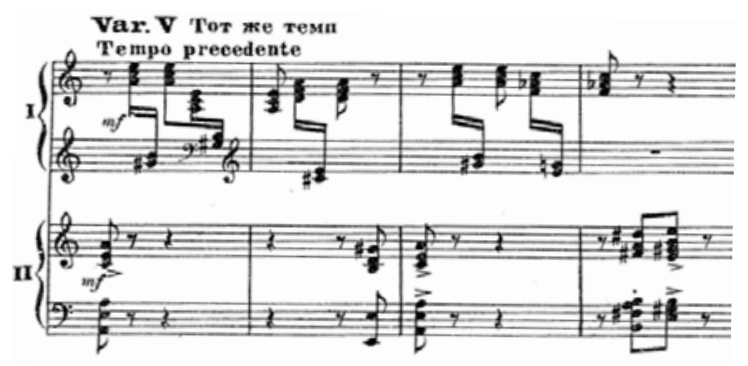

[Figure 4.3] Variation 5

- Variation 6: Having good fingerings and efficient hand distribution will be helpful to execute tricky passages much easier.
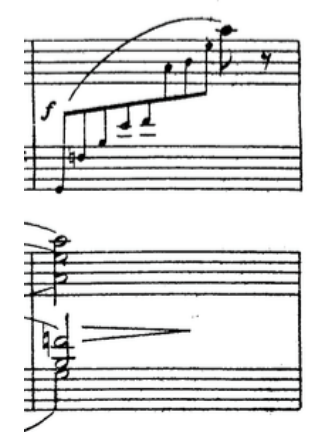

[Figure 4.4] Four bars after rehearsal 14:

[5-1]-[1-2-3-5]-[5-3-1]

(LH) (RH) (LH)

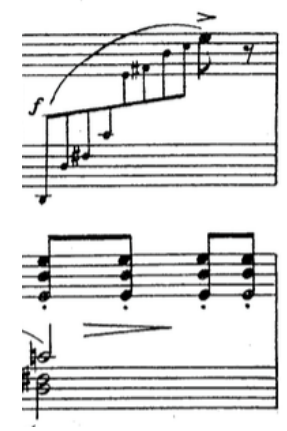

[Figure 4.5] Twelve bars after rehearsal 14:

[5-1]-[1-2-4-5]-[3-2-1]

(LH) $\quad(\mathrm{RH}) \quad(\mathrm{LH})$ 


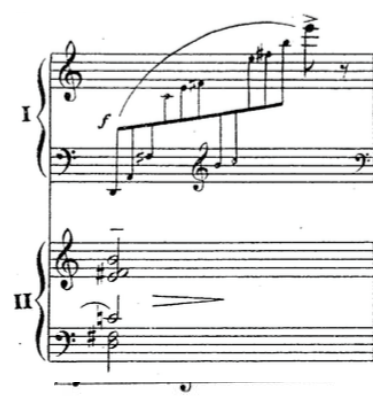

[Figure 4.6] Four bars after rehearsal 15:

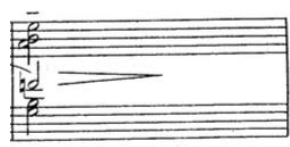

[5-2-1]-[1-2-4-5]-[5-2-1]-[1-2-5]-[3]

$(\mathrm{LH}) \quad(\mathrm{RH}) \quad(\mathrm{LH}) \quad(\mathrm{RH})(\mathrm{LH})$

[Figure 4.7] Four bars after rehearsal 16:

[5-1]-[1-3-5]-[4-2-1]-[1-2-5]-[3]

$(\mathrm{LH}) \quad(\mathrm{RH}) \quad(\mathrm{LH}) \quad(\mathrm{RH})(\mathrm{LH})$
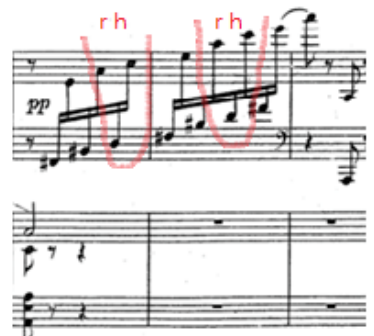

[Figure 4.8] Five bars after rehearsal 17:

$\begin{array}{llllllllllllllllll}\text { RH } & & 1 & 2 & 3 & 4 & & 1 & 2 & 3 & 4 & & 1 & 4\end{array}$

All of these arpeggio runs should sound effortless. You may lean on the first note and gradually accelerate for the first four examples. The last one (Example 5) should sound strictly even.

- Variation 8: First decide fingerings that are most natural and comfortable on your hand, then lock in that hand position. Fingering suggestion for the right hand follows: 

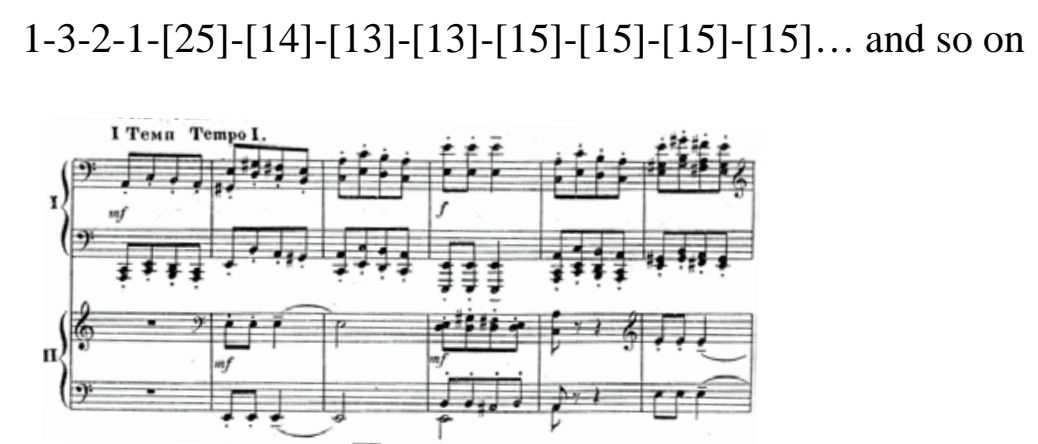

[Figure 4.9] Variation 8

- Variation 9: Keep the exciting rhythmic drive from the previous variation. Also hear the down beat in the orchestra/piano II, and make sure to have the same tempo and pulse to synchronize. Practice frequently with a metronome in order to stay strictly steady.

- Variation 13: This variation is full of energy with a ff dynamic, and big leaps from one chord to the next. To play these leaps with ease, move your whole upper body in the direction the chords are heading. This will also allow you to play with much more power as you are playing with the weight of your body.

- Variation 14, Piano solo section: Have efficient fingering. The tempo should not be too fast. It is better to have a reasonable tempo to play every note with precision and excitement than to play extremely fast and lose all the nuances. If the tempo becomes the priority, listeners would not know what to listen for. The section should be vibrant and brisk, but in a tempo you can control. A quarter note around 138-144 is plenty fast. Since this section is piano solo, you can take some rubato in places where stylistically appropriate. This variation is the end of section II. Make sure you breathe and take enough time to change the mood for the next section.

- Variation 17: This variation could sound boring if you do not bring out the embedded melodic line in broken triads. Decide which line to bring out. I suggest bringing out each down beat most of the time. When the down beat stays in the same note and other notes are moving, 
bring out those changing notes. Another way is to bring out the quarter notes that are embedded in the broken triads. However, it could get tricky because these are not always the downbeat. Use your best musical intuition to make it expressive.

- Variation 18: The eighteenth variation is the culmination of the piece. It has to be extremely romantic and expressive. Use plenty of rubato. The key factor of this section is voicing. Bring out the melody and play the accompaniment as softly as possible. At rehearsal 50, listen for the orchestra as it has the melody. When performing with piano accompaniment especially, check for balance even though piano I has forte and piano II has $m f$ dynamic marking. Make sure piano II projects the melody while piano I provides powerful support for the melody. The fingering and hand distribution is also important when the melody enters, as there are hand overlaps in the accompaniment part. The notes in the right hand are lower than those in the left hand. Therefore, some adjustment is required in order to play them comfortably and bring out the beautiful melody as much as possible. The following suggestion will be helpful:

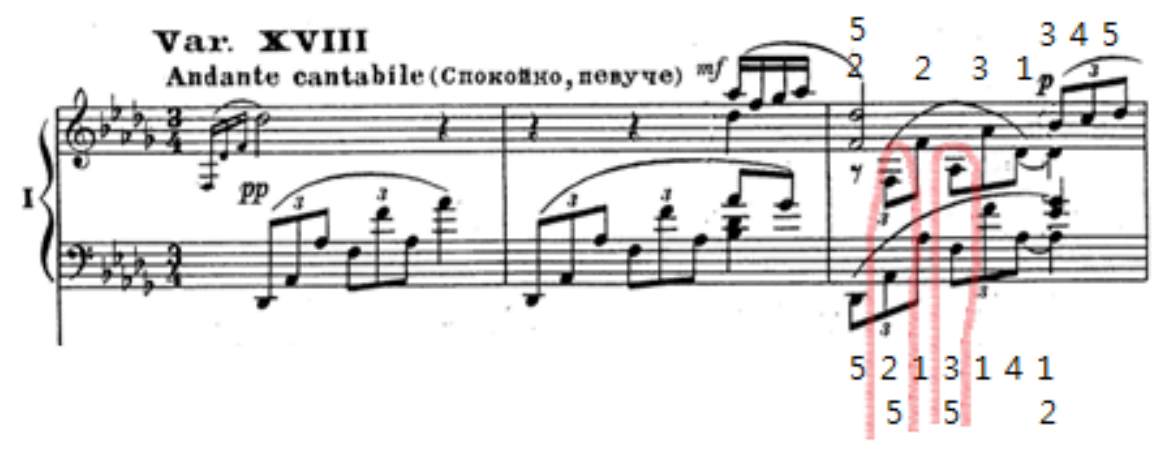

Playing the low F and A with your left hand helps to bring out the melody in legato. Repeat that fingering for the rest when it is applicable.

- Variation 19: The final group of variations (Vars. 19-24) becomes increasingly virtuosic. Variation 19, marked quasi pizzicato, depicts one particularly well-known aspect of Nikolai 
Paganini’s fabled technique. ${ }^{19}$ It also features a sudden and dramatic dynamic contrast between $p$ and $f$. Playing the first, third, and fourth triplets with the right hand, and second triplet with the left hand for the first seven measures of the variation will give you some idea on fingering and how the rest should be played. The bottom line is that you do not need to cross over your thumb all the time. Distribute them between two hands if possible.

- Variation 21: Variation 20 and 21 are diabolical in character. Tempo should be somewhere between 152-160 to the quarter note. It shows off one’s good and precise finger work. Use your fingers only when playing single notes, and use wrists when playing passages in octaves. Show big dynamic contrast— the ascending arpeggios are the preparation for the following three big chords. Think of it as if you are shooting off fireworks.

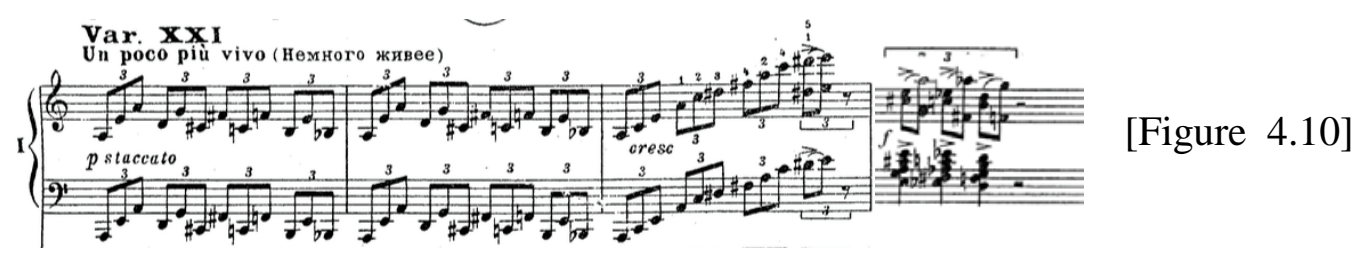

- Variation 22: The final group of the variations is generally longer than the first and middle groups. Variation 22 is one of the longest variations which features many different techniques. It begins with a series of march-like chords, then trains of scales, followed by arpeggio passages, and finally reaches to a short piano cadenza with octave passages. Rachmaninoff seamlessly connects this variation to the next with a half cadence.

- Variation 23: The tonal center of the short cadenza in Var. 22 is A-flat. Rachmaninoff plays around with A-flat and A minor tonality back and forth between solo and orchestra, and

${ }^{19}$ Martyn, 330. 
finally returns to A minor at rehearsal 69. This variation has two big ascending scales in octaves. Play them with low wrists - low enough that your fingers and the keyboard become almost perpendicular. Adjust the position when hitting F\# (Figure 4.11).

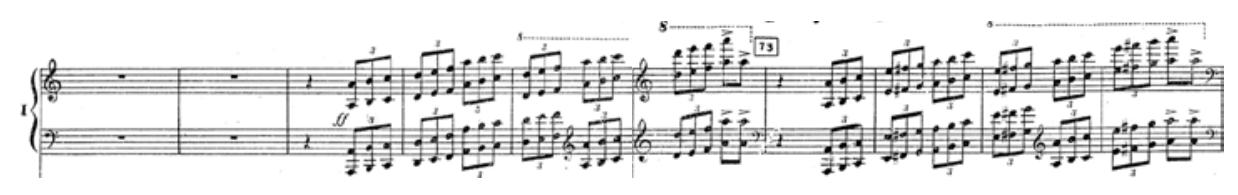

[Figure 4.11] Variation 23

- Variation 24 + coda: The last variation opens with another reference to the real-life Paganini and his playing in the unmistakable imitation of a violin figure. Even Rachmaninoff himself seems to have had some difficulty in mastering its final skip. ${ }^{20}$ The tempo should not be too fast. A quarter note $=108-116$ is reasonable. Rhythmic practice will help with accuracy. Also wrist motion takes a huge role here. Play them as if you are turning a door knob. The tempo accelerates as it reaches to the coda. Pedal with the downbeat and release it quickly for the first eight measures of più vivo. Dies irae comes back at rehearsal 78 in the orchestra, and the piano has both the thematic material and the melodic outline of Dies irae. Play the coda with extremely flexible wrists and hit the keyboard as if it is drums, especially for the last section, rehearsal 79. After its intensity reaches the climax, the final two measures should be quiet and decisive. These final gestures come from the introduction, and Rachmaninoff ends the Rhapsody with a repetition of it.

${ }^{20}$ Martyn, 331. 
The Paganini Rhapsody shows Rachmaninoff at the height of his powers. The coherence of its structure, the ingenuity and resourcefulness shown in the treatment of its musical material, and the brilliance but discretion of its scoring command a respect not lessened by the overfamiliarity the work’s popularity inevitably creates. ${ }^{21}$

${ }^{21}$ Martyn, 332. 


\section{CHAPTER FIVE: \\ VARIATIONS ON A THEME BY PAGANINI FOR TWO PIANOS (1940-41), FOR PIANO AND ORCHESTRA (1978) BY WITOLD LUTOSŁAWSKI}

\section{BACKGROUND}

Witold Lutosławski (1913-1994), a Polish composer and conductor, is one of the major European composers of the twentieth century. Lutosławski began his career as a composer shortly before the Second World War. During The German occupation of Poland, Polish cultural life went underground. The Germans had banned public concerts, and serious music-making could only be heard in cafés. Warsaw’s cafés (kawiarnie) provided virtually the only public forum for Polish soloists, and it was in such establishments that Lutoslawski was forced to make his living for the next four and a half years. In the years of 1940-1944, Lutosławski and his peer Andrzej Panufnik, (1914-1991) often performed piano duets together. Their repertoire consisted not of light café music but rather of arrangements of serious works on which the two composers collaborated, embracing a variety of musical styles. The duo made some two hundred arrangements, from Bach organ works to Debussy and Ravel, and even Stravinsky, as well as traditional jazz motives; and included in that repertoire was Lutoslawski’s two piano transcriptions of Paganini's 'Caprice No. 24' ${ }^{22}$ Being the better pianist, he designed the first pianist's part for himself and the easier second part for Panufnik. ${ }^{23}$ This arrangement was created in 1941 and premiered in the same year.

\footnotetext{
${ }^{22}$ Felix Aprahamian, Program notes, Lutosławski: Variation on a Theme of Paganini for Two Pianos, Chester music, August, 1982.

${ }^{23}$ Steven Stucky, Lutoslawski \& His Music (Cambridge University Press, 2009), 16.
} 
Lutoslawski's version of the Paganini variations is somewhat similar to that of Liszt in that they both follow the same structure of the original caprice of Paganini. In other words, Brahms and Rachmaninoff create a totally new version of variations by only using the thematic material of the caprice, while Liszt and Lutosławski follow the structure of the original works and transcribe it according to their own musical tastes. While Lutosławski's transcription of the variations has a traditional underpinning, the compositional devices he uses are typical of the twentieth century. In 1977, Lutoslawski revised this composition as a Concerto for Piano and Orchestra at the request of the pianist, Felicja Blumental, who gave the first performance on November 18, 1979 in Miami, with the Florida Philharmonic Orchestra. The orchestrated version is very similar to the two piano versions. Lutosławski made very little change in the musical substance. According to Lutosławski himself, the orchestrated version expands the piano-duo piece by repeating each section (except for the theme and Variations 10 and 11), with the soloist and orchestra exchanging roles for the second time through each variation.

Of the roughly two hundred such pieces they concocted together, all but the Paganini Variations perished in the Warsaw Uprising. It is ironic that the Paganini Variations, which were a mere by-product of Lutosławski's wartime café playing, have achieved a prominent place in the duo-piano repertoire and have become by far the composer's most frequently recorded work. $^{24}$

${ }^{24}$ Ibid. 


\section{GENERAL ANALYSIS}

\subsection{Structure}

Lutosławski's set follows the structure of the original caprice but he added one more variation before the coda, which powerfully restates the theme for the last time. The work closely follows the original motive of each variation. Each variation has two sections, eight measures each, except for Variation 10 which has thirty two measures, sixteen measures for each section. Since Lutosławski augmented the value of the melody from the original, the number of measures was also increased.

In terms of indicating variation numbers, Lutoslawski is the only one who omitted numbers for each variation among the five selected composers. Instead, he put a double bar after each variation.

\section{$\underline{2.2 \text { Harmony and Tonality }}$}

In keeping with the original caprice, the variations are tonal, but Lutoslawski overlays the diatonic scaffolding with chromaticism and compositional devices of the twentieth century, such as polytonality. ${ }^{25}$

Lutoslawski's version of the Paganini variations is far distinguished from the three previous compositions for its harmonic dimension as well as its style in general. He rendered the piece with chromatic and dissonant harmonies, accented syncopation, polyrhythm, polytonality, and ostinati. As to its harmony, the piece naturally relies on A minor, in relation to which the chordal textures, not having much in common with major-minor tonality, become a type of

\footnotetext{
${ }^{25}$ Andrzej Chłopecki, "Variations on a Theme of Paganini.” Witold Lutosławski, http://www.lutoslawski.org.pl/en/composition,7.html (accessed July 22, 2017).
} 
atonal and purely timbre-oriented variation that pervades the entire composition. ${ }^{26}$ The theme itself is strictly in A minor, but Lutoslawski deviates from using diatonic accompaniment, and chooses to use non-diatonic chords such as F major seventh chords against E major, D major with a sixth with A minor, and so on (Figure 5.1). Because Lutosławski uses these clashing chords so often, the work may seem to have no tonal center. Yet, between Piano I/Soloist and Piano II/Orchestra, one always has an A minor tonality, which reinforces the tonal center of the work. Furthermore, dominant-tonic cadences are commonly used throughout the work. The dominant is most often represented by a poly-chord superimposing the Neapolitan and dominant functions.

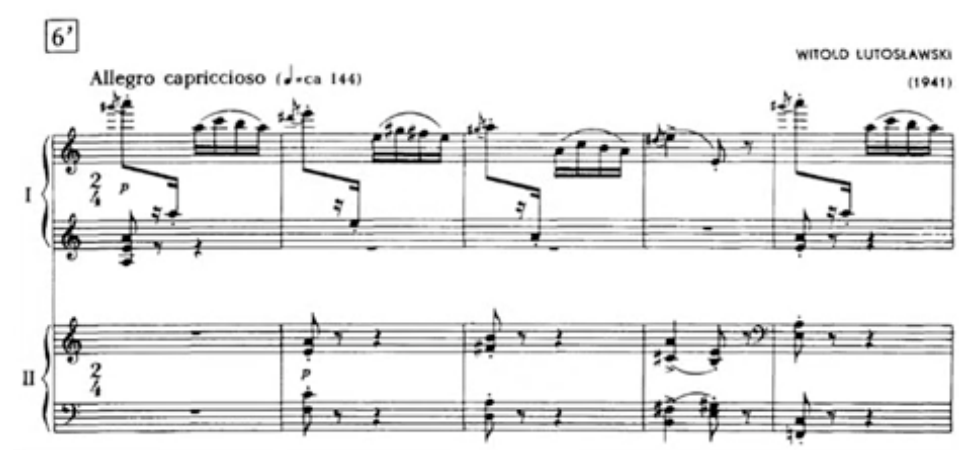

[Figure 5.1] Theme

Thus, a vertical harmonic analysis does not help to understand Lutoslawski’s harmonic choices for the piece in this case. Rather, one should pay close attention to chords he chose and understand how they affect its texture with the theme. Polytonality between the two keyboards is frequent, often involving triads whose roots lie a tritone apart. This compositional device is shown in the B section of the Theme, and in the third variation where he uses polytonality entirely. ${ }^{27}$

\footnotetext{
${ }^{26}$ Ibid.

${ }^{27}$ Stucky, 17.
} 
In the third variation, the first piano begins in A major while the second piano starts in A-flat major as shown in figure 5.2.

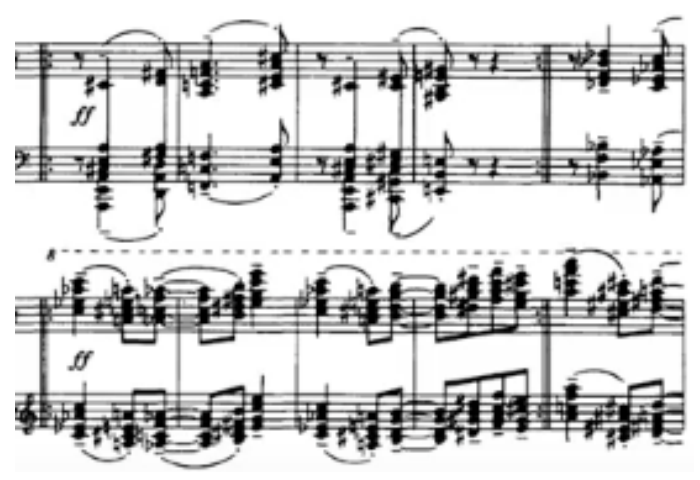

[Figure 5.2] Polytonality in Variation 3

In addition, Lutosławski incorporates the use of parallel motion, particularly parallel fifths, throughout the entire piece. From the theme until the third variation, chords that retain open fifths are more apparent and they tend to move chromatically.

\subsection{Rhythm, Tempo, and Dynamics}

One of the significant rhythmic interests Lutoslawski incorporates in this work is the use of ostinato in the accompaniment. This gives the piece a twentieth-century compositional style. In Variations 7, 8, and 10, each of the melodies is accompanied by an ostinato figure. Variation 10 especially becomes very mechanical with ostinato accompaniment, which is reminiscent of “Winnsboro Cotton Mill Blues” from Four North American Ballads by Frederic Rzewski for a brief moment, in terms of a precise and mechanical rhythmic style. 


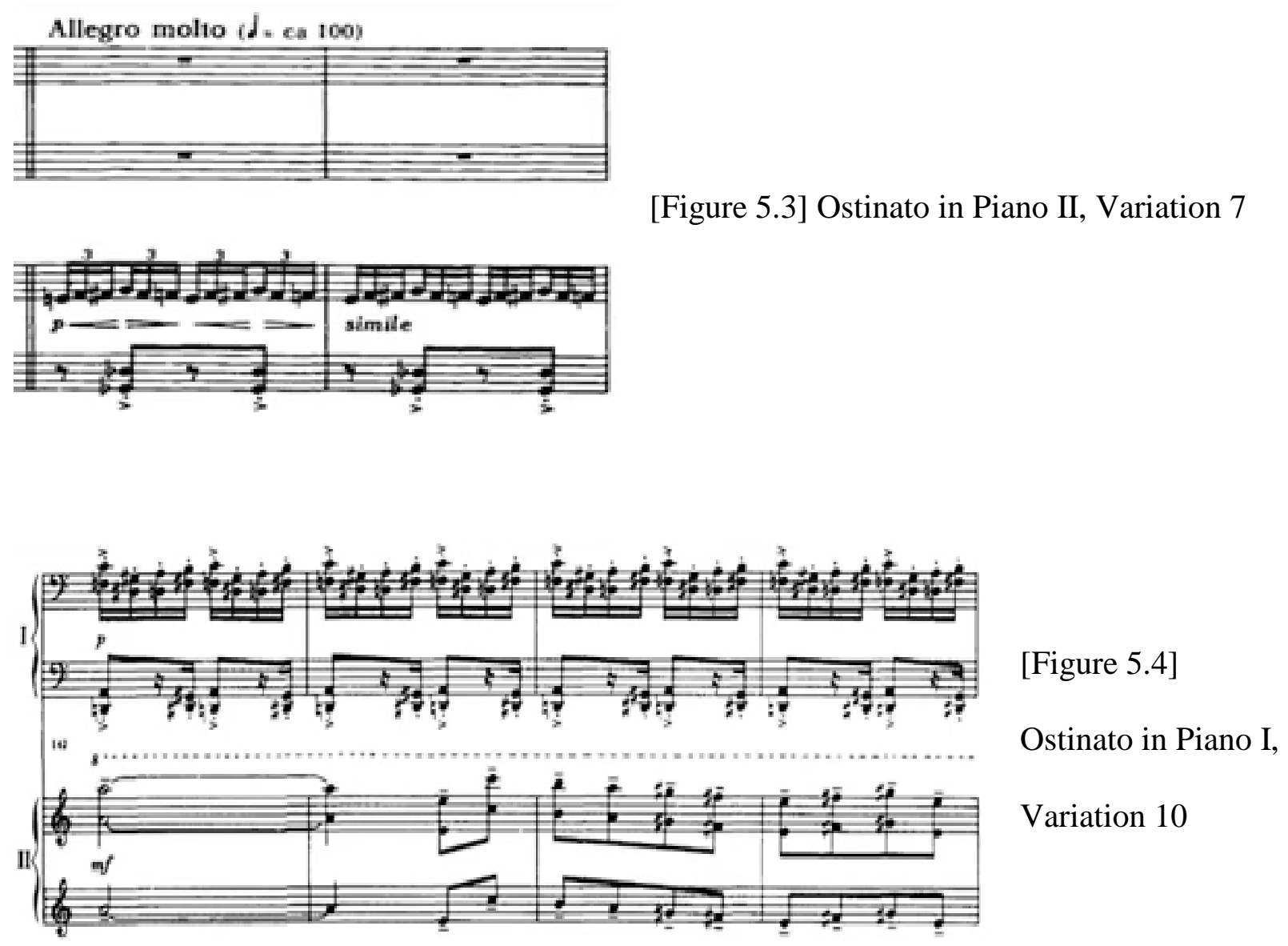

Lutosławski suggests tempi for the work, and he uses a total of six different tempo indications throughout work. It is a common practice in the twentieth century that composers indicate specific tempo markings and detailed performance guidelines for their compositions. In the sixth variation, Lutosławski writes Poco lento and states ca. 80 for an eighth note. The original Paganini caprice has quasi presto at the beginning but does not specify performance tempo. Regardless, the sixth variation of the Lutosławski's version has a completely new and different mood. Unlike the original caprice which starts in forte, Lutosławski treated the sixth variation as a soft and delicate one. The second piano has the melody, and is accompanied by the 
first piano in its inversion in parallel triads. It is written in the style of a canon. Since Piano I has the inverted melody, the canon is moving in contrary motion.

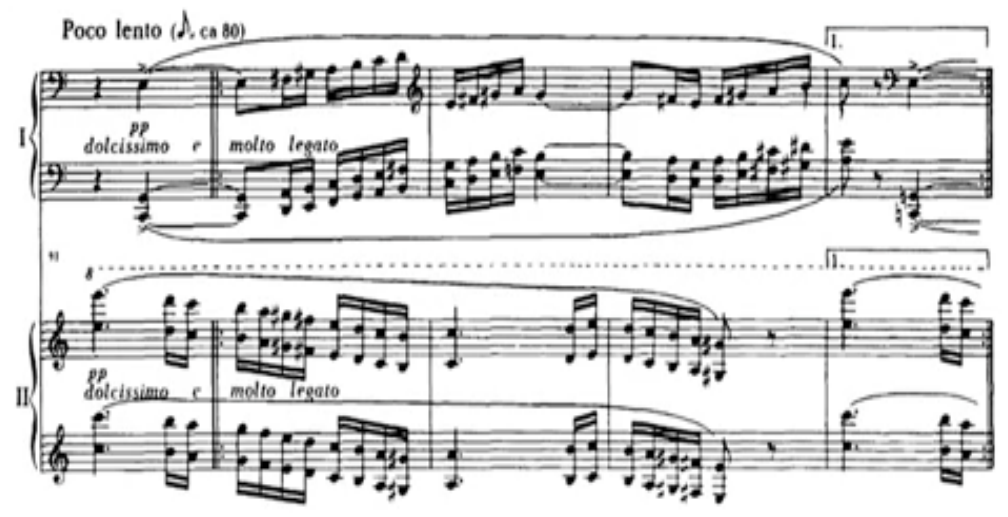

[Figure 5.5] Canon in a contrary motion, Variation 6

Lutoslawski’s use of dynamics is highly imaginative and shows twentieth-century nuances (irregular accents, sudden dynamic changes, and so on). For the most part, the piece follows the same mood of the original Paganini caprice, but there are two variations he alters from the original. Variations 6 and 8 are in the opposite mood from the caprice. As mentioned earlier, the sixth variation is the softest in dynamic. Variation 8 of Lutosławski's version starts softly in piano and gradually grows to forte while Paganini indicates its dynamic in forte. His use of accents is not traditional and clearly exemplifies the twentieth-century writing style and the influence of jazz music. Variation 9 especially has irregular accents, including 3+3+2 accents, which are common in jazz music. 


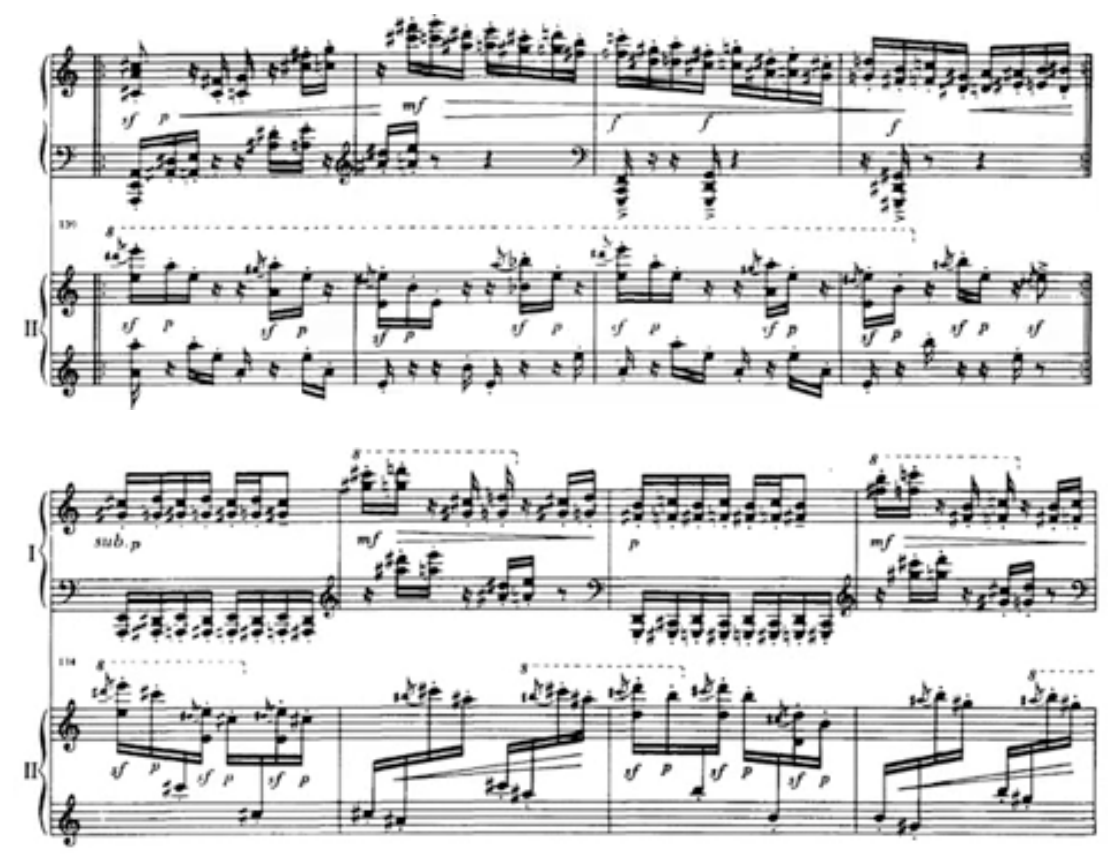

[Figure 5.6] Variation 9 with irregular accents

\section{PEDAGOGICAL SUGGESTIONS}

\subsection{Level of Difficulty}

Lutosławski's set of Paganini Variations itself is not an easy piece but it is probably the least difficult one among the selected five compositions. Piano I is more challenging than Piano II for its pianism—continuous thirds and seconds (Var. 4), consecutive fourths and fifths (Vars. 9 and 10) and so on. Piano II has a relatively easier part since it does not require difficult piano techniques. It has skips in general, ostinato figures (Vars. 7 and 8), hand tremolo (Var. 11), and glissandi (Var. 12) which are not overly challenging. This piece may be suitable from college level intermediate (preferably Piano II) to advanced students. The work is about six minutes long, and is one of the staple repertoires for a duo-piano recital.

When performing with orchestra, the piece becomes little more difficult, and it is most suitable for advanced students. Playing with two pianos, each performs only his part. With 
orchestra however, each variation is repeated twice and the soloist and the orchestra change their parts the second time. As a result, the soloist must learn both Piano I and II.

\subsection{Performance and Pedagogical Guidelines}

Lutosławski's duo piano version and the later version with orchestra have their own characteristics. Although it is the same composition indeed, they sound very different. The orchestrated version obviously has wider sound spectrum with different timbres of instruments.

- Theme: It is straightforward and the melody is very similar to the original. The accompaniment in the second piano adds harmonic twist. One should pay attention to the dynamic contrast in the B section.

- Variation 1, Second piano: Bring out the open chords in the left hand for harmonic support.

- Variation 2:

- First piano: Completely relax your wrists to perform hand tremolo. Practice slowly with metronome first with rhythmic precision and gradually pick up tempo because your body needs to adapt the coordination between the hands.

- Second piano: Emphasize the sforzandos.

- Variation 4, Piano I: This is one of the trickiest variations in the set along with Variations 9 and 10 in terms of fingering. It is better to use bouncing wrists than fingers only. For the right hand, grab the first thirds with thumb and fourth fingers, and the following seconds with second and third fingers. Keep this fingering and play the passages as if you are playing a slow trill. 


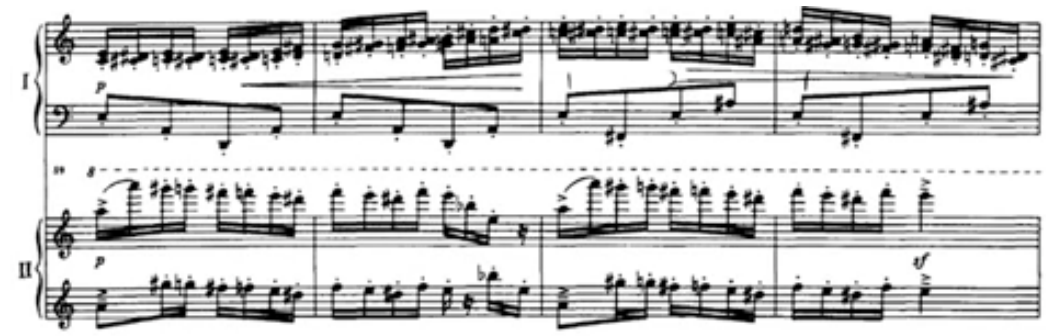

[Figure 5.7] Variation 4

- Variation 6: This variation is highly contrapuntal with canonic writing. It should sound like ringing bells. Piano II should bring out the top notes and play as smoothly as possible. Be careful with using too much rubato because you and your partner might not have the same pulse which can cause unevenness of sixteenth notes. Try connecting the melodic line with fingers with touches of pedal. Do not start rallentando too soon.

- Variation 7, Piano II: Completely change the mood from the previous variation. Use circular motion of the right hand wrist to play the "bumble bee" figure. Bring out upbeat accents in the left hand.

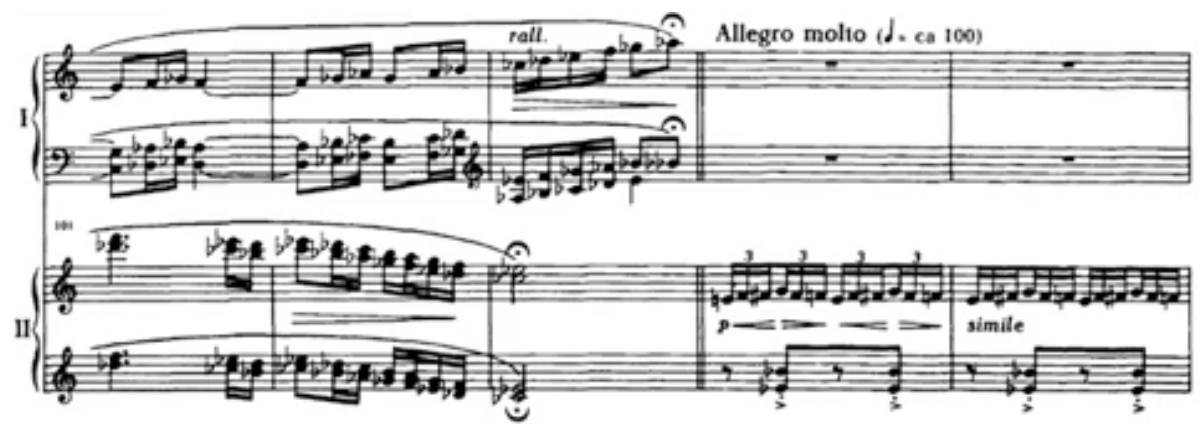

[Figure 5.8] End of variation 6/ beginning of variation 7

- Variation 8, Piano I: Pace out the crescendo.

- Variations 9 and 10, Piano I: This variation and the preceding variation contain the most twentieth-century techniques with irregular syncopation and accents as well as ostinato. These 
two variations are probably the most challenging ones for the entire set in terms of skips and fingerings. In Variation 10, the first piano has a tricky fingering. Use the following fingering and repeat.

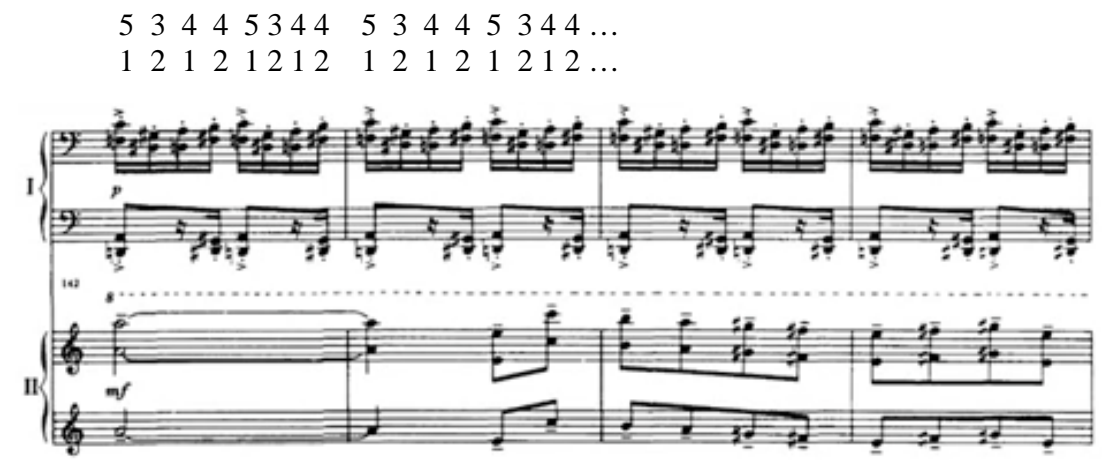

[Figure 5.9] Variation 10

The skips in the left hand become more difficult as the variation proceeds. Practice in rhythms, try using a kinetic/motoric memory of one hand and focus on the other hand only while playing.

- Variation 11: Practice the arpeggiated/scale passages with metronome for both parts to synchronize precisely.

- Variation 12: Even though Lutosławski did not write an accelerando marking, you may gradually pick up a tempo four measures before Variation 12 in order to play the following variation in tempo. There are three glissandi in the second piano. The first glissando is on the third beat but other two glissandi are off the beat. They should follow right after the chord in the left hand. Think to play almost at the same time with the chord so the downbeat in the next measure is not late. 
- Coda, the last four measures, Piano II: While Piano I has hand tremolo in fff, it is hard for him/her to hear the descending chromatic scale of the second piano. Connect with each other to check the pulse by either nodding or inhaling deeply before the playing the scale. 


\section{CHAPTER SIX: \\ DESPERATE MEASURES FOR PIANO, OP. 48 (1994) BY ROBERT MUCZYNSKI}

\section{BACKGROUND}

Paganini’s Violin Caprice No. 24 has provided a rich seam of material for works by subsequent composers throughout the centuries. Other than Lutosławski, there are a number of twentieth-century composers whose compositions are based on the Paganini theme. Lowell Liebermann (b.1961) and Robert Muczynski (1929-2010) are among them.

Liebermann wrote Rhapsody on a Theme of Paganini for piano and orchestra (2001). Although the title has usually been associated with Paganini’s twenty-fourth caprice, Liebermann's set does not use the twenty-fourth caprice as the thematic motive, but it is based on the melody of La campanella - Liszt's Grand Paganini Etudes No.3. The melody of La campanella originally comes from the final movement of Paganini’s Violin Concerto No. 2 in B minor. The work displays Liebermann's distinctive musical characteristics such as adventurous harmonies, bitonality, ostinato, haunting melody and timbre, as well as pointillism.

Robert Muczynski’s Desperate Measures, Op. 48 for Solo Piano (1994) is one of the major works in the twentieth century that incorporates Paganini’s twenty-fourth caprice. His set consists of a theme and twelve variations. Like Brahms and Rachmaninoff, Muczynski creates his own set based on the melodic motive of the caprice. The work has tonal harmonies although it features many contemporary compositional devices such as bitonality and bimodality, change 
of modes, tone clusters, quartal and quintal harmonies, change of meters, parallelism, and synthetic scales. ${ }^{28} \mathrm{~A}$ more detailed analysis will be discussed later in this chapter.

Unlike the works of many other twentieth-century composers, Muczynski’s musical style defies specific categorization or stereotyped labels. His works are frequently labeled as Neoclassic, Neo-romantic or Neo-Baroque, but how his music is categorized depends upon the particular piece. It is not, therefore, easy to distinguish his specific musical models from more general influences. As the composer explained himself: "Such matters as style and influences in my work cannot easily be labeled owing to the fact that a composer's creative efforts/outlook undergo constant change over a span of some thirty-seven years!” ${ }^{29}$ His colleague, Richard Faith, mentioned that Muczynski admired Beethoven and Liszt when he was young, and later it was Prokofiev, Bartók, Barber, and Copland. He also favored Vivaldi, Haydn, Chopin, Brahms, Franck, Debussy, Shostakovich, and Hindemith. He also enjoyed American popular music style such as Gershwin and Max Steiner, a film composer. ${ }^{30}$ Composers in our time often explain their compositional intentions to audiences and scholars for them to have better understanding of their compositional process and musical philosophy. Muczynski, however, left the discovery of his techniques and influences to performers and audiences themselves, as he was disinclined to discuss his own musical ideas or techniques in public. ${ }^{31}$ He complained, “[I wish] academia would stop trying to x-ray music and just let it be... who really cares about the 'how' when it's

\footnotetext{
${ }^{28}$ Kwang Sun Ahn, “An Analytical Study of the Variations on The Theme of Paganini's Twenty-Fourth Caprice, Op. 1 by Busoni, Friedman, and Muczynski” (D.M.A diss., University of North Texas, 2000), 70.

${ }^{29}$ Kiyono M. Bernier, "Desperate Measures: Two 20th Century treatments of the Paganini Theme” (D.M.A. diss., University of Arizona, 2000), 58; Muczynski's correspondence to the author in a phone interview, February 22, 1990.

${ }^{30}$ Ibid, 59.

${ }^{31}$ Ibid, 58.
} 
only the 'what' that counts?”32 Although his musical style cannot be categorized in a certain genre, his music is never atonal. Muczynski is essentially a tonal composer, although the sonorities and harmonic progressions are typical of the twentieth century. ${ }^{33}$

Muczynski’s style of writing for the piano is highly idiomatic. As an accomplished pianist, he is well aware of the various capabilities of his chosen instrument. He utilizes its full expressive range, from an eloquent lyricism to a highly motoric and percussive style. His works can be demanding technically, with abrupt leaps in register, fast passage work, and multi-layered textures, in addition to the detailed articulation, dynamic, pedal and expressive markings. However, his works usually sound more difficult than they are to play. ${ }^{34}$

\section{GENERAL ANALYSIS}

Muczynski completed Desperate Measures (Paganini Variations), Op.48, for piano in June 1994 in Tucson, Arizona. He dedicated this music to his sister, Gloria. Regarding the title “Desperate Measures”, the composer commented on the piece as following:

"It was 1992 and I was at a loss of what direction to take. Over the years, I had produced a considerable amount of solo piano music as well as sonatas and trios for instruments and all sorts of combination. One evening, I was enjoying a drink with a good friend and I remarked, 'I know it may sound like a silly idea, but ever since I was a music student, I had this notion of doing some piano variations on the Paganini Caprice, and now I think I like to have a crack at it! I must be desperate!' That is how the title and the pun evolved. My variations are not grand etude like, not European born (Brahms, Liszt and Rachmaninov). I think of them more as entertainment.”35

\footnotetext{
32 Gregory Christian Kostraba, “The First Piano Trio by Robert Muczynski” (D.M.A. diss., University of Cincinnati, 2003), 8.

${ }^{33}$ Valerie C. Cisler, “The Piano Sonatas of Robert Muczynski” (D.M.A. diss., University of Oklahoma, 1993$), 418$. 34 Ibid.

35 Bernier, 65; Muczynski’s correspondence to the author in a phone interview, February 22, 1990.
} 
Perhaps for this reason, his set of Paganini variations sounds more informal and freer in terms of style and structure than those by the four previous composers.

\subsection{Theme}

Muczynski preserves the original structure of the theme $(4+4+8)$, but adds repetition of the B section, thus $4+4+8+8$. He presents the theme an octave higher than Paganini and reinforces the fifth relationship (A and $\mathrm{E}$ ) in the left hand. In the B section, the counter melody in the left hand follows the harmony based on the circle of fifths. Muczynski keeps the original thematic line intact, but he slightly alters the last two measures. He uses a harmonic minor scale with a raised fourth, often called the Hungarian minor scale or Gypsy minor scale.

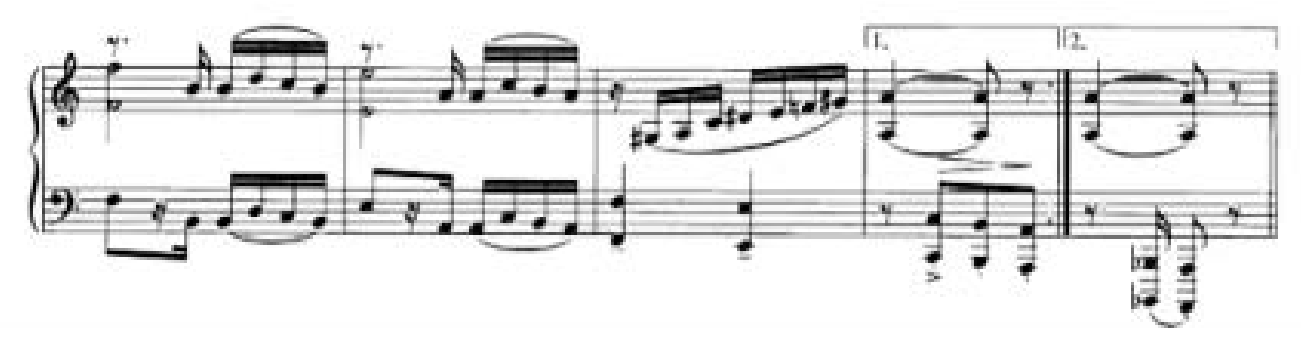

[Figure 6.1] Gypsy minor scale in the Theme

\subsection{Structure}

Muczynski's treatment of the structure is different than those of the four previous composers. The variations of Liszt, Brahms, Rachmaninoff, and Lutoslawski are mostly organized into two sections, each containing eight measures or sometimes sixteen measures when repeated. In other words, the theme and its variations all have a symmetrical form. Muczynski also writes some of the variations in the same manner, eight measures of the A 
section, sometimes repeated, followed by another eight measures with a repeat or written-out sixteen measures for the B section. The theme, and Variations 1, 4, 6, and 7 completely follow this structure. However, he does not always adhere to this traditional form. He adds/subtracts one or a few measures, or sometimes completely deconstructs it. Variation 2 has the traditional eightmeasure-long A section, but the B section has only six measures with a repeat. Variation 3 has a sixteen-measure-long B section but only a four-measure-long A section. Variations 5 and 8 have an extra measure at the end. Variations 9 to 12 completely deviate from the tradition.

Furthermore, Muczynski incorporated several distinctive styles in this piece. Therefore, the work can be divided into four sections by style. :

Section I: Theme, Variations 1, 2, and 3

Section II: Variations 4, 5, and 6

Section III: Variations 7, 8, and 9

Section IV: Variations 10, 11, and 12

Section I is mostly traditional in terms of structure and harmony. The melody is also quite conjunct. Section II is more adventurous than Section I for its harmonic choice and disjunct melodies. Section III is written in the style of popular and jazz music. Muczynski himself indicates Variation 8 in the style of a Tango. Section IV is quite innovative in terms of structure and harmonic idioms. Variation 10 especially showcases the twentieth-century harmonic idiom and texture. 


\subsection{Harmony}

Muczynski's use of harmony is both traditional and innovative at the same time. Sonorities are based on the harmonic idioms of the late nineteenth and early twentieth centuries. For his chordal choice, he frequently adds seventh and ninth chords based on the tertian harmonies. Furthermore, he experimented with sounds from the upper partials of the overtone series, incorporating widely spaced eleventh and even thirteenth chords. He also used harsh dissonances which are typically the result of melodic movement of inner voices or above a static bass (ostinato or pedal point). There are also many instances of using added-notes, parallelism, bitonality, quartal and quintal harmonies, and concurrent use of major and minor thirds. ${ }^{36}$

Another characteristic of Muczynski’s harmonic vocabulary is his tendency toward tonal ambiguity which he approaches by a sudden change in chord quality; by using added tone chords especially utilizing minor seconds, tritones and major sevenths; by using bi-chords and equidistant chords; by using non-functional chord progressions and non-traditional cadence preparation; and by using remote relationships among the various pitch centers of the pieces. His harmony also has a jazz flavor, which can be identified by the use of consecutive seventh chords of various kinds and blues scales. ${ }^{37}$

Muczynski incorporates exotic scales in this work. As mentioned earlier, he uses a Gypsy minor scale in the Theme. Besides that, he features an octatonic scale in this work, as found in Variation 8 (See Figure 6.2).

\footnotetext{
${ }^{36}$ Ahn, 73.

${ }^{37}$ Ibid.
} 
For the harmonic accompaniment in the left hand, Muczynski frequently uses quartal harmony as shown in Variations 3, 4, 7, and 8.

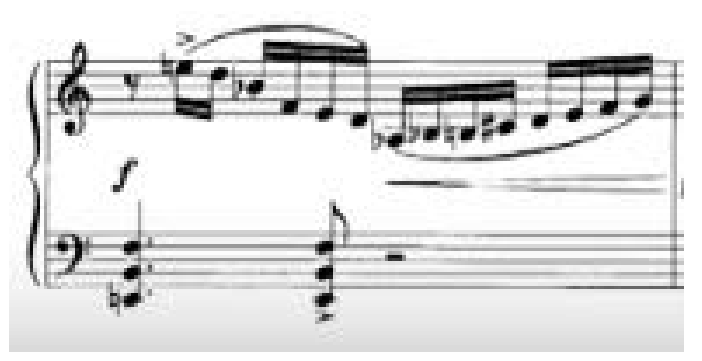

[Figure 6.2] Variation 8, Octatonic scale in the right hand and quartal harmony in the left hand

\subsection{Meter and Rhythm}

The most different aspect about Muczynski’s set of Paganini variations in contrast to those of Liszt, Brahms, Rachmaninoff, and Lutosławski, would be his rhythmic choice and frequent changes of meters as well as his fondness for using irregular meters such as 5/8 and 3/8. Variation 6 features the most frequent meter changes. The B section stays in 6/8 throughout but the entire A section has meter changes in every measure, shifting between $3 / 8$ and $4 / 8$ with the exception of 3/4 and 2/4 in the middle. In spite of the fast meter shifts, the basic pulse remains consistent, usually counted in quarter or eighth notes (See Figure 6.3). ${ }^{38}$

\footnotetext{
${ }^{38}$ Ahn, 79.
} 


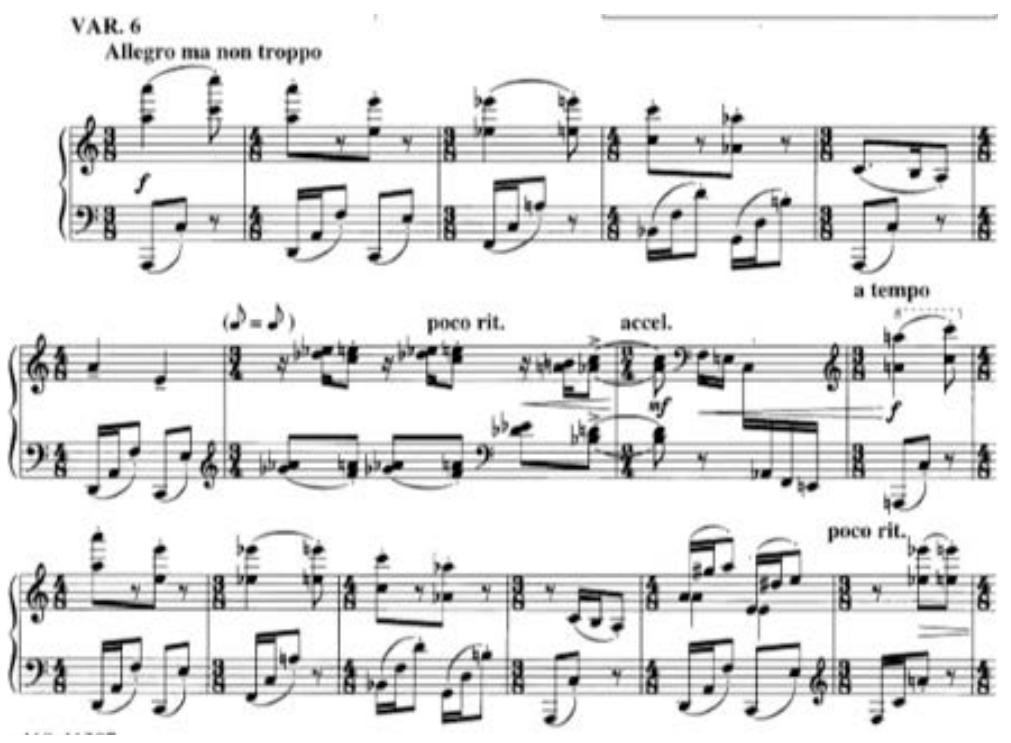

[Figure 6.3] Variation 6 features frequent meter changes

Muczynski's use of rhythm is best described by David Brin in his article. Brin explains as following:

“Driving, vigorous rhythms are Robert Muczynski’s trademark. In his music meters may change frequently, but the rhythms are never contrived. While not easy to perform, there is something so natural about these rhythms that they create their own momentum, carrying the performers along, never leaving them grasping for the beat.”39

As Brin illustrates, Muczynski’s set seems to be quite complex at first sight due to its meter. Yet, it is reasonably manageable when actually played. Also, his writing is very idiomatic in that all of the notes fit naturally and comfortably in the fingers.

39 David M. Brin, “In Print,” Strings 5, No. 2 (September-October 1990): 13. 
Another interesting rhythmic twist Muczynski uses is the placement of accents on off beats, for example, Variation 1 and 10 near the cadence (See Figure 6.5).

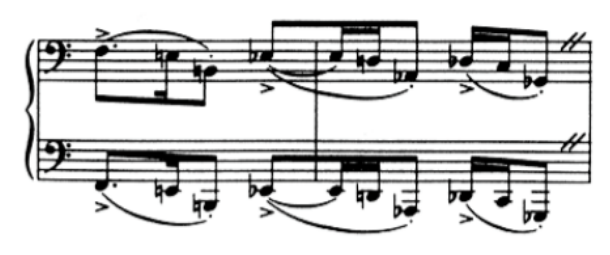

[Figure 6.5] Variation 1 near the final cadence

Muczynski's use of continuous sixteenth notes or eighth notes results in motoric rhythm in general. One of the rhythmic figurations he uses frequently in the set is a sixteenth rest on the downbeat followed by seven sixteenth notes (Figure 6.4).

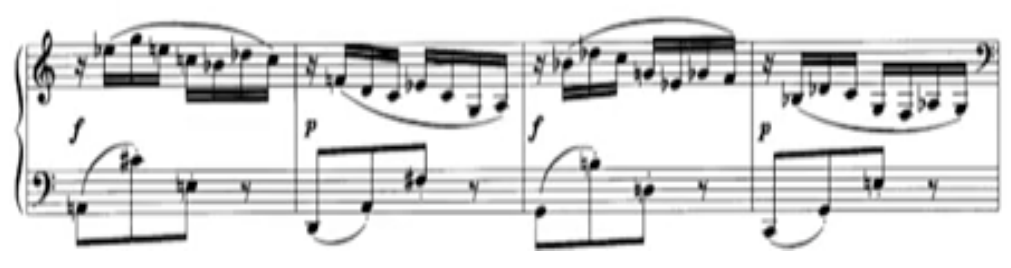

[Figure 6.4] Sixteenth-note figuration

\section{PEDAGOGICAL SUGGESTIONS}

\subsection{Level of Difficulty}

Desperate Measures displays multiple styles which may be viewed as Postmodernistic in manner. The piece would be less difficult than Liszt's, Brahms's, and Rachmaninoff's versions technique-wise, but the challenging aspect about this work is to execute the different styles effectively. For instance, if one does not feel comfortable playing in a jazz style, and plays Variations 7, 8, and 9 in the same style as playing traditional classical music style, this piece can seem far more difficult than it actually is. At any rate, the difficulty level of this piece would 
rank after Lutosławski among the five selected pieces, mainly in terms of technique. It also could be a great starter piece for advanced college-level music students who do not have a lot of experience playing the twentieth-century pieces. This familiar tune with its varied modifications will hold the students' attention and help them to naturally acquire the twentieth-century musical style.

\section{$\underline{3.2}$ Performance and Pedagogical Guidelines}

Although Muczynski himself does not divide this piece into sections, practicing in sections can be effective for better understanding of multiple styles and for memorization.

\section{Section I:}

- Variation 1: In the A section, play the staccatos in the left hand with thumb. The key in this variation is to bring out the dynamic contrast. A short pause at two measures before the final cadence could be timed — count two or three eighth-note rests before proceeding.

- Variation 2: Pay attention to the rhythmic accents - third beat in the A section, and second beat in the B section before changing to 6/8.

- Variation 3: Play as percussive as possible for the A section. In the B section, bring out the embedded melodic line in the left hand. Suggested fingering is:

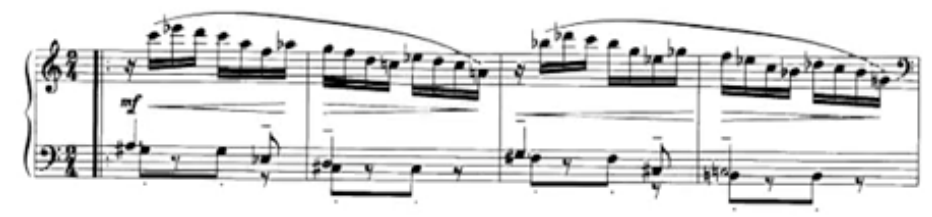

[Figure 6.5]

$\begin{array}{lllllllllll} & 1 & & & 1 & & 1 & & 1 & \\ \text { L.H } & 2 & 2 & 3 & 4 & 4 & 2 & 2 & 3 & 4 & 4\end{array}$




\section{Section II:}

- Variation 4: This scherzando variation is in 6/8. The first chord in the left hand (A, E, A, B) is from the previous variation. Play as lightly as possible and articulate staccatos and slurs.

- Variation 5: Variation 5 is the most expressive one in the set. It is legato entirely. The melody is quite disjunct. Decide how you would want to phrase the melody and practice with much rubato. There are two options to play the last note, D-natural. You can gently press down the key and leave your finger down until the sound vanishes. The other way is to ring the Dnatural as if you are plucking the key in outward motion. This should feel like a water drop hitting a lake.

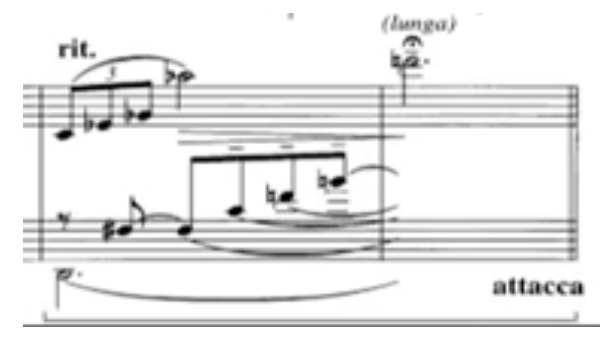

[Figure 6.6]

- Variation 6: It breaks away from the consistent meters from the previous variations. Although the meter changes constantly, the number of measures in A section and B section remain traditional— sixteen measures each. Keep the eighth note steady, as it becomes your pulse for counting.

\section{Section III:}

- Variation 7: Slow down the tempo a little bit since the composer marked it as "relaxed". A quarter note may be between 56 and 63 in metronome marking. This variation features 3+3+2 rhythm, typical in jazz music. The A section is divided into two styles. The first four measures 
are legato and the following four measures are staccato with two-note slurs in the left hand. In order to bring out the melody, play the melody in forte and accompaniment in mezzoforte. It would be easier if you let the fifth finger/fourth finger (depending on which finger you use to bring out the melody) be the center of the weight or as an anchor point.
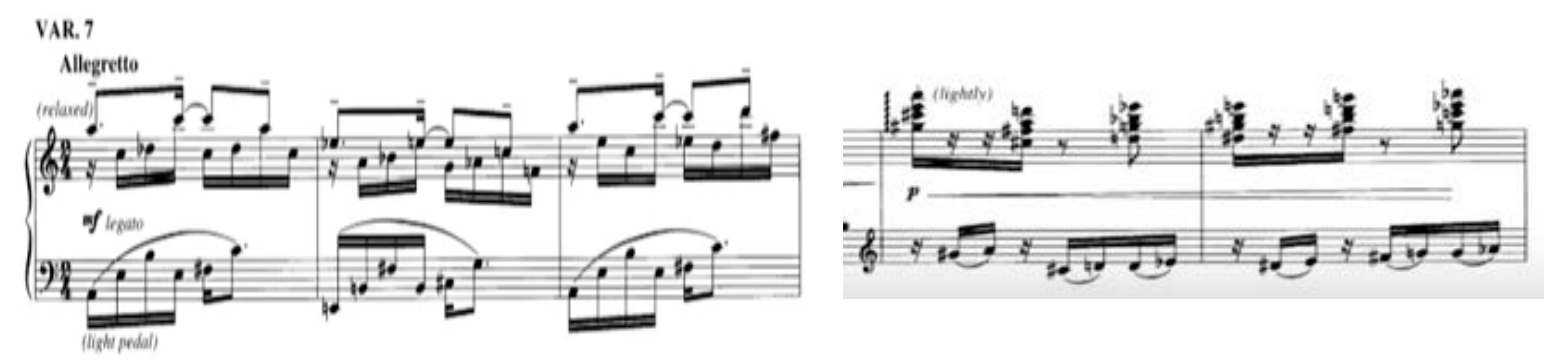

[Figure 6.7]

- Variation 8: Inserting dance forms in theme and variations has been a common practice for centuries and Muczynski adds one in his eighth variation. The tango is an Argentine genre of urban song and dance music that remained popular throughout the twentieth century. ${ }^{40}$ The music of the tango, frequently in a minor mode, is one of abrupt rhythmic and dynamic contrasts. In a typical tango accompaniment, a prevailing pattern in which all beats are sharply accented will be occasionally interrupted by sudden pauses and by syncopated passages. ${ }^{41}$ In regards to tempo, this can be even more relaxed than Variation 7, with a quarter note between 48 and 52. Be careful with pedaling for rests and phrase articulation. In general, you should change pedal by harmony. When there is a whole-note octave/dotted half note in the left hand, you may use a long pedal, but use your own discretion to prevent a muddled sound.

\footnotetext{
40 Bernier, 81.

${ }^{41}$ Ibid.
} 
- Variation 9: It is a slow waltz. However, it is not a typical waltz which has a strong down beat followed by two weak beats. Instead, Muczynski uses 9/8 and 6/8 meters and get the triplet going as an undercurrent rhythm. The jazzy section III generally has constant poco rit. and $a$ tempo. Make sure they flow naturally. Do the ritardando moderately. Save a big ritardando for the final cadence. There are two places where the sixteenth-note runs are quite tricky.

Therefore I suggest the following fingerings: Measure 9 and measure 11 of Variation 9.

(*Measure numbers are counted by each variation)

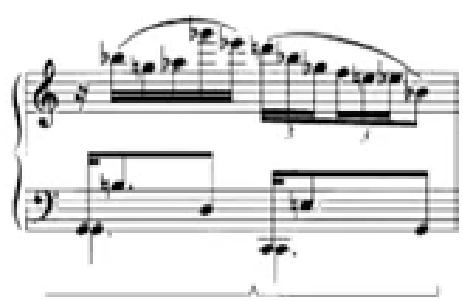

R.H: 31254532132

[Figure 6.8]

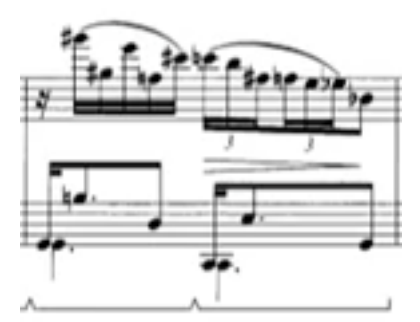

R.H: 515135421321

[Figure 6.9]

Measure 10 of Variation 9 may move forward a little bit at the head of the measure, but not too much in order to execute the poco ritandando more dramatically. The same procedure could be applied in measure 14 .

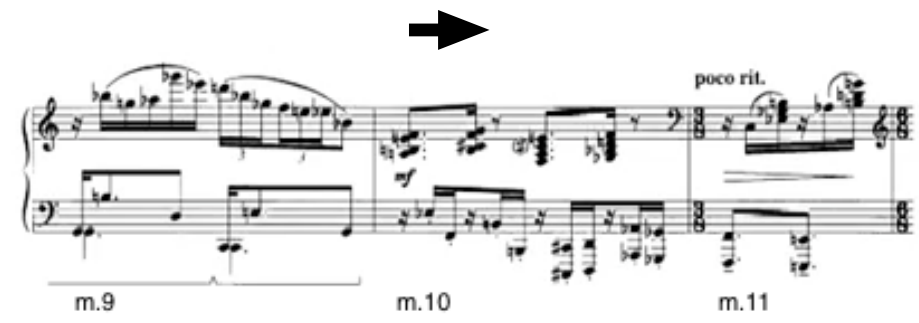

[Figure 6.10]

\section{Section IV:}

- Variation 10: Instead of presenting the theme in melodic form, Muczynski uses minor seventh and diminished seventh chords. It begins Andante and gradually picks up. At the repeat of the 
A section, the tempo is already set to Allegro. Pedal with slurs in the left hand in the A section. For the first four measures in the B section, pedal for the first down beat. Measure 25 is another place where the accents are placed on offbeats. Makes sure to keep the pulse and tempo steady.

- Variation 11: Along with Variation 5, this is another slow legato variation. It starts with the first five notes of the original melody (A-C-B-A-E), but quickly departs from it. In terms of dynamics, this should be as quiet and still as possible. The following Variation 12 with coda is powerful and big, and Muczynski put the softest variation before it as calm before the storm. To manage a soft sound, fingers should stay close to the keyboard. You may also use una corda pedal at measure 7 and at the end of the variation where they are $p p$ in dynamic level.

- Variation 12: Muczynski brings the Paganini theme back in this final variation. The sixteenthnote figuration that he favors to use at the beginning also comes back in full force. The left hand accompaniment is already presented in the previous variation and Muczynski reuses it in this one. Measures 5 and 6 give a false cadence to audience. The repeat of the melody at the following measure starts in piano. It has to be subito, and very soft so that there is room to grow in sound. There are quite a bit of tempo indications for the last section. These tempo changes should be natural and nicely flowing. Measures 25-30 are marked as Moderato, the slowest section in this variation. Treat it as a throwback before it hits the last flourish of the theme. 

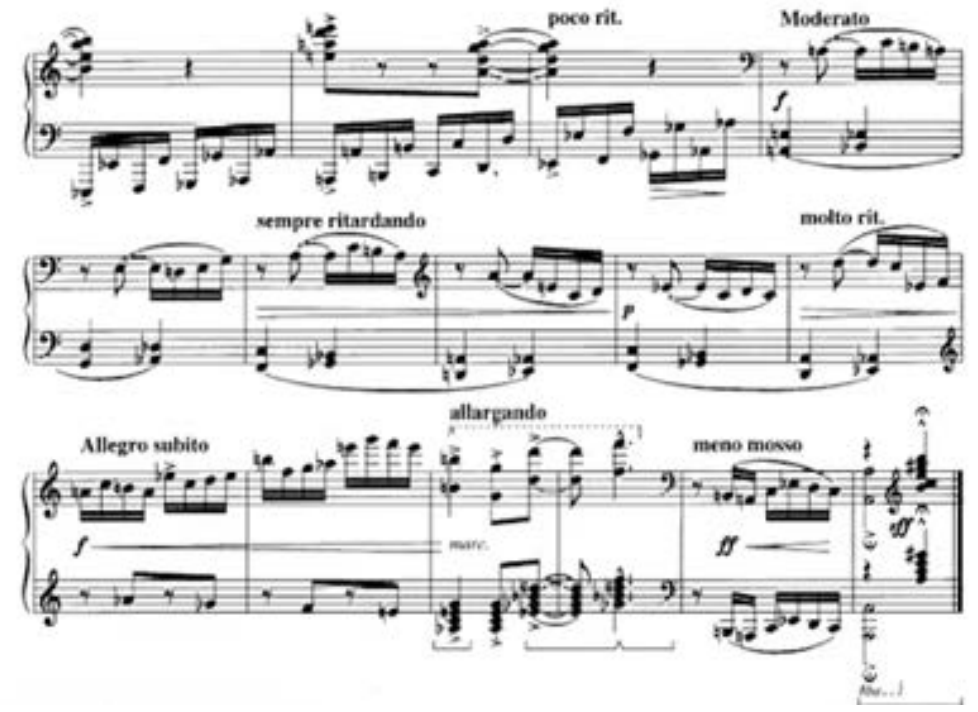

[Figure 6.11] 


\section{CHAPTER SEVEN: \\ SUMMARY AND CONCLUSION}

By looking at the five different compositions based on the twenty-fourth violin Caprice by Niccolo Paganini, one can realize that this enchanting theme has unlimited charms to offer. There are still more composers nowadays who are writing their works based on this theme. The Paganini theme has such a great establishment as compositional inspiration not only in classical music but also in popular music including soundtracks of films or TV shows.

Beginning with Liszt, the piano version of the famous variations was born. He was so inspired by Paganini’s virtuosic violin playing, and decided to transcribe it. It is the most true to the original. His first version, Études d'exécution transcendante d'après Paganini, S.140 (1838) is not often performed anymore, compared to the second version, Grandes études de Paganini, S. 141 (1851), because of its outrageous difficulty. After Liszt thinned out and revised the first version, the second version became the final product, and therefore is performed more often than the original set. Regardless, both versions surely require the dexterity of a skilled performer. It is the shortest one of the selected five compositions in this paper, but is full of challenges indeed.

Brahms’ two sets of Paganini variations are perfect concert repertoires for their length and bravura display. Unlike Liszt, Brahms created his own versions with the borrowed theme. In performance, it is common to play both as a set as the composer wrote them. But another possibility is to carefully select variations from both versions by considering continuity of the music, length, and so on.

Both Liszt's and Brahms’ sets of variations have substantial virtuosic display, a typical style of the nineteenth century. As a piano instrument had more advanced development, the piano as an instrument saw significant developments in its construction during the nineteenth 
century, and it caused the piano music of the time to flourish even more, aiming for more bravura. Performing techniques such as rapid skips, runs in thirds, sixths, and octaves, and even combinations of these are often presented in their sets. Harmonically, these two mostly stay in A minor or closely related keys, and do not depart far from it.

Rachmaninoff's turn for the Paganini theme is little bit more adventurous. First, he added orchestra. Also, he titled it as a "Rhapsody" instead of "Variations.” According to Grove Music Online, a rhapsody is a one-movement work that is episodic yet integrated, free-flowing in structure, featuring a range of highly contracted moods, color and tonality. An air of spontaneous inspiration and a sense of improvisation make it freer in form than a set of variations. ${ }^{42}$ Rachmaninoff's Paganini Rhapsody indeed satisfies this description. With its free theme-andvariations form, the work has four distinctive sections. It surprisingly bears the style of the concerto or symphony, which usually has four movements with contrasting tempos and moods. One can assume that since Rachmaninoff wrote the work for piano and orchestra, he perhaps had followed a similar structural design.

Comparing the Rhapsody with the variations of Liszt and Brahms, its harmonic idiom is more creative and departs farther from the original tonal center. Although Rachmaninoff put variation numbers in, it sounds as if he through-composed the work. The variations of Liszt and Brahms sound strictly as theme and variations: theme followed by a number of independent variations while Rachmaninoff's version sounds as if the theme gradually develops and transforms to the next idea.

\footnotetext{
42 John Rink, “Rhapsody,” Grove Music Online, ed. S. Sadie and J. Tyrrell, accessed August 29, 2017, http://oxfordmusiconline.com
} 
Paganini Variations by Lutosławski deviates from the nineteenth-century style of writing. Use of repeated patterns, percussive texture, polytonality, syncopated rhythm, and irregular accents emphasize his twist of the traditional nineteenth-century music. Lutosłaski's set is stylistically somewhere between Liszt and Rachmaninoff. It is similar to that of Liszt in that he transcribed the original, but also similar to the version of Rachmaninoff in the fact that he wrote for solo with accompaniment. Lutoslawski then incorporates his own prism of sounds and completes the piece with his unique musical flair. This piece sounds more difficult to the ear than it actually is to play, which could be a delightful treat for a performer.

Lastly, Desperate Measures by Muczynski is the most recent version of the Paganini theme (among the selected five works in this study). It showcases some degrees of postmodernism, featuring pointillism and insertion of the jazz style. Muczynski’s set sounds tremendously different from the other four works. The theme is fairly intact from the original, but the melodic figures in the following variations are quite deconstructive. Yet, when taking a close look at the formal and harmonic structures of his set, he does not completely deviate from the original. It sounds very different not because he does not religiously follow the formal and harmonic structures of the original, but because he uses extreme dissonance, rearranged melodic lines, and incorporates jazz harmony.

Each of the five selected works based on the theme of Paganini’s Violin Caprice No.24 exhibits its own uniqueness and does not need to be compared to anything for its own significance. They represent the five composers' different musical styles and their philosophies. They come from different places and times, but their music shares one thing in commoncreating an imaginative musical journey through the theme of Paganini. 


\section{APPENDIX:}

List of compositions based on Caprice No. 24 in A minor by Nicolo Paganini:

- $\quad$ Rafał Augustyn - Paganini Variations for solo piano (1987-1989) (reference: www.polmic.pl)

- $\quad$ Luc Baiwir - Variations on a Theme by Paganini, for solo piano (2007)

- James Barnes - "Fantasy Variations on a Theme by Niccolo Paganini", a wind band arrangement with each variation as a solo for a particular section

- $\quad$ Isaak Berkovich - Variations on a Theme by Paganini, for solo piano (1950)

- $\quad$ Boris Blacher - Variations on a Theme by Paganini (1947), for orchestra

- $\quad$ Hans Bottermund - Variations on a Theme by Paganini

- Johannes Brahms - Variations on a Theme of Paganini, Op. 35 (1862-63), for solo piano (Two books)

- $\quad$ Charles Camilleri - Paganiana, for two pianos

- $\quad$ Ignaz Friedman - Studies on a Theme of Paganini, Op. 47b (1914)

- $\quad$ David Garrett - "Paganini Rhapsody" (2007)

- $\quad$ Marc-André Hamelin - Variations on a Theme by Paganini for solo piano (2011)

- $\quad$ Lowell Liebermann - Rhapsody on a Theme of Paganini for piano and orchestra (2001)

- $\quad$ Franz Liszt - the sixth and last of his Études d'exécution transcendante d'après Paganini for solo piano, S.140 (1838) - revised and republished in 1851 as Six Grandes Études de Paganini, S.141

- $\quad$ Andrew Lloyd Webber - Variations (1977), Variations (album) originally for cello and rock band, and used as the theme for The South Bank Show, later also arranged for cello and orchestra; Song \& Dance - the Dance part is a reworked version of Variations

- Witold Lutosławski - Variations on a Theme by Paganini (1940-41), for two pianos; in 1978 he made a version for piano and orchestra

- $\quad$ Denis Matsuev - Caprice No. 24 variations, Denis Matsuev Quartet, jazz (2010)

- $\quad$ Nathan Milstein - Paganiniana 
• $\quad$ Robert Muczynski - "Desperate Measures" Paganini Variations, Op.48

- $\quad$ Paolo Pessina - Paganini Variations, for Violin (and Piano 'ad libitum') "to Ruggiero Ricci", Op. 25 (1997)

- $\quad$ Gregor Piatigorsky - Variations on a Paganini Theme, for cello and orchestra (1946), later arranged for cello and piano

- $\quad$ Simon Proctor - "Paganini Metamorphasis" for Solo Piano

- $\quad$ Frank Proto - Capriccio di Niccolo for Trumpet and Orchestra (1994). Nine Variants on Paganini for Double Bass and Orchestra, also for Double Bass and Piano (2001). Paganini in Metropolis for Clarinet and Wind Symphony (2001), also for Clarinet and Orchestra (2002)

- $\quad$ Manuel Quiroga - 9 Variations on Paganini's Caprice No. 24; 12 Variations on Paganini's Caprice No. 24 for violin and piano

- $\quad$ Sergei Rachmaninoff - Rhapsody on a Theme of Paganini, Op. 43 (1934), a set of 24 variations for piano and orchestra

- $\quad$ George Rochberg - 50 Caprice Variations (1970) for solo violin

- $\quad$ Alexander Rosenblatt - Variations on Theme of Paganini for solo piano (1988)

- $\quad$ Poul Ruders - Paganini Variations: Guitar Concerto No. 2 (1999-2000), 22 variations for guitar and orchestra

- $\quad$ Ehsan Saboohi - Metamorphosis on Theme of Paganini for solo piano (2009)

- $\quad$ Faz1l Say - Paganini Jazz in Say Plays Say for solo piano (1988)

- $\quad$ Stanisław Skrowaczewski - Concerto Nicolò for Piano Left Hand and Orchestra (2003)

- $\quad$ Karol Szymanowski - No. 3 from Trzy kaprysy Paganiniego (3 Caprices de Paganini), Op. 40 (1918); transcriptions for violin and piano

- $\quad$ George Thalben-Ball - "Variations on a Theme of Paganini" Theme and 10 variations for Pipe organ

- $\quad$ Philip Wilby - Paganini Variations, for both wind band and brass band

- $\quad$ Hans Wurman - "13 Variations on a Paganini theme" for synthesizer on The Moog Strikes Bach (1969) 
- $\quad$ Eugène Ysaÿe - Variations on Paganini's Caprice No. 24, for violin and piano, op. posthumous

- $\quad$ JJ Lin - "Variation 25: Clash of The Souls", a song from album "Lost N Found" (2011) 


\section{BIBLIOGRAPHY}

Ahn, Kwang Sun “An Analytical Study of the Variations on The Theme of Paganini's TwentyFourth Caprice, Op. 1 by Busoni, Friedman, and Muczynski.” D.M.A. diss., University of North Texas, 2000.

Altman, Ian Henry. "Liszt's Grand Etudes After Paganini: A Historical and Analytical Study.” D.M.A. diss., University of Cincinnati, 1984.

Arnold, Ben. The Liszt Companion. Westport, CT: Greenwood Press, 2002.

Bernier, Kiyono Monique. "Desperate Measures: Two 20th Century Treatments of the Paganini Theme.” D.M.A. diss., The University of Arizona, 2000.

Bertensson, Sergei and Jay Leyda. Rachmaninoff. New York: New York University Press, 1956.

Brin, David M. “In Print,” Strings 5, (1990): 13

Chen, Ling Chao. “An Analysis of Witold Lutoslawski's 'Variations on a Theme by Paganini' for Two Pianos and an Original Composition 'Concerto for Two Pianos and Orchestra'.” D.M.A. diss., Louisiana State University and Agricultural \& Mechanical College, 1996.

Chłopecki, Andrzej. "Variations on a Theme of Paganini." Witold Lutosławski, http://www.lutoslawski.org.pl/en/composition,7.html (Accessed July 22, 2017).

Chou, Chien. "Variation Procedure in Rachmaninoff's Piano Works.” D.M.A. diss., Boston University, 1994.

Chou, Szu-Ting. “The Influence of the Theme and Variation of Paganini's 'Caprice no.24' from 'Twenty-Four Caprices for Solo Violin’ on Two Major Piano Solo Works: Liszt 'Grandes Etudes De Paganini no.6 in A Minor, S.140’ and Muczynski 'Desperate Measures (Paganini Variations) for Piano, Op.48’.” M.M. Thesis, The University of Texas at San Antonio, 2012.

Chuang, Hsiang-I. “The Brahms-Paganini Variations, Op.35: The Continuation of Paganini's Virtuosity in Piano Music.” D.M.A. diss., The University of Wisconsin at Madison, 2008.

Cisler, Valerie C. “The Piano Sonatas of Robert Muczynski.” D.M.A. diss., University of Oklahoma, 1993.

Clavere, Javier. “A Study Guide to Franz Liszt's 'Grandes Etudes de Paganini’ S.141.” D.M.A. diss., University of Cincinnati, 2011.

Evans, Edwin. Handbook to the Pianoforte Works of Johannes Brahms. New York: Lenox Hill, 1970. 
Gordon, Stewart. A History of Keyboard Literature: Music for the Piano and its Forerunners. New York; London: Schirmer Books, 1996.

Hershberger, Jay Alan. "Rachmaninoff on Rachmaninoff: An Interpretive Analysis of His Piano/Orchestra Recordings.” D.M.A. diss., Arizona State University, 1995.

Kang, Heejung. "Rachmaninoff's 'Rhapsody on a Theme by Paganini, Op. 43': Analysis and Discourse.” D.M.A. diss., University of North Texas, 2004.

Kim, Younshin. “An Analytical Study of Liszt's 'Grandes Etudes De Paganini’, Nos. 3 and 6.” D.M.A. diss., University of Washington, 1999.

Ko, Cha-Hui. "Solutions to Technical Difficulties in the Rhapsody on a Theme by Paganini, Opus 43 of Rachmaninoff.” D.M.A. diss., The Ohio State University, 1997.

Kostraba, Gregory Christian. “The First Piano Trio by Robert Muczynski.” D.M.A. diss., University of Cincinnati, 2003.

Martyn, Barrie. Rachmanioff: Composer, Pianist, Conductor. New York: Routledge, 2016.

Oh, Joo Young. “An Introduction to Selected Character Pieces for Piano by Robert Muczynski.” D.M.A. diss., University of Arizona, 2016

Robertson, Gillian. "Variations on a Theme by Paganini: Narrative Archetypes in Nineteenthand Twentieth-Century Theme-and-Variation Sets.” Ph.D. diss., The Florida State University, 2015.

Stucky, Steven. Lutoslawski \& His Music. Cambridge University Press, 2009.

Tovey, Donald Francis. Essays in Musical Analysis: Chamber Music. London: Oxford University Press, 1944.

Tse, Benita Wan-Kuen. "Piano Variations Inspired by Paganini's Twenty-Fourth Caprice from Op. 1.” D.M.A. diss., University of Cincinnati, 1992.

Zhang, Ying. “A Stylistic, Contextual, and Musical Analysis of Rachmaninoff's Rhapsody on a Theme of Paganini, Op. 43.” D.M.A. diss., Rice University, 2008.

Zhou, Wenli. "Piano Variations by Liszt, Lutoslawski, Brahms, and Rachmaninoff on a Theme by Paganini.” D.M.A. diss., Rice University, 2012. 


\section{Program/Liner Notes}

Aprahamian, Felix. Program notes to Lutosławski: Variation on a Theme of Paganini for Two Pianos. Chester Music, 1982.

Howard, Leslie. Liner Notes to The Complete Music for Solo Piano, Vol. 48: Liszt- The Complete Paganini Études, Leslie Howard. Hyperion CDA 67193. CD. 1998.

\section{Scores}

Brahms, Johannes. Variation on a Theme by Paganini, Opus 35. Johannes Brahms: Sämtliche Werke, Band 13: Sonaten und Variationen für Klavier zu zwei Händen. Plate J.B.57. Leipzig: Breitkopf \& Härtel, 1926-27.

Franz, Liszt. Grandes études de Paganini, S.141. Musikalische Werke. Serie II, Band 3. Plate F.L. 38. Leipzig: Breitkopf \& Härtel, 1911.

Lutoslawski, Witold. Variations on a Theme by Paganini for Two Pianos. London: Chester Music, 1949.

Mucyznski, Robert. Desperate Measures (Paganini Variations) for Piano, Opus 48. Bryn Mawr, PA: Theodore Presser Company, 1996.

Paganini, Nicolo. 24 Caprices for Solo Violin Opus 1. Ed. Abram Yampolsky. Moscow: Muzyka, 1988.

Rachmaninoff, Sergei. Rhapsody on a Theme by Paganini, Opus 43. Plate 2346. Moscow: Muzyka, 1979. 